\title{
Fragmentation of Singly, Doubly, and Triply Charged Hydrogen Deficient Peptide Radical Cations in Infrared Multiphoton Dissociation and Electron Induced Dissociation
}

\author{
Anastasia Kalli, Sonja Hess
}

Proteome Exploration Laboratory, Division of Biology, Beckman Institute, California Institute of Technology, Pasadena, CA 91125, USA

\begin{abstract}
Gas phase fragmentation of hydrogen deficient peptide radical cations continues to be an active area of research. While collision induced dissociation (CID) of singly charged species is widely examined, dissociation channels of singly and multiply charged radical cations in infrared multiphoton dissociation (IRMPD) and electron induced dissociation (EID) have not been, so far, investigated. Here, we report on the gas phase dissociation of singly, doubly and triply charged hydrogen deficient peptide radicals, $[\mathrm{M}+\mathrm{nH}]^{(\mathrm{n}+1)+\cdot}(n=0,1,2)$, in $\mathrm{MS}^{3}$ IRMPD and EID and compare the observed fragmentation pathways to those obtained in $\mathrm{MS}^{3} \mathrm{CID}$. Backbone fragmentation in $\mathrm{MS}^{3}$ IRMPD and EID was highly dependent on the charge state of the radical precursor ions, whereas amino acid side chain cleavages were largely independent of the charge state selected for fragmentation. Cleavages at aromatic amino acids, either through side chain loss or backbone fragmentation, were significantly enhanced over other dissociation channels. For singly charged species, the MS ${ }^{3}$ IRMPD and EID spectra were mainly governed by radical-driven dissociation. Fragmentation of doubly and triply charged radical cations proceeded through both radical- and charge-driven processes, resulting in the formation of a wide range of backbone product ions including, $a-, b-, c-, y-, x-$, and $z$-type. While similarities existed between $\mathrm{MS}^{3} \mathrm{CID}$, IRMPD, and EID of the same species, several backbone product ions and side chain losses were unique for each activation method. Furthermore, dominant dissociation pathways in each spectrum were dependent on ion activation method, amino acid composition, and charge state selected for fragmentation.
\end{abstract}

Key words: Hydrogen deficient peptide radical cations, Infrared multiphoton dissociation, Electron induced dissociation, Radical driven, Charge driven, Aromatic residues

\section{Introduction}

G as phase dissociation of hydrogen deficient peptide radical cations has emerged as an exciting area of

Electronic supplementary material The online version of this article (doi:10.1007/s13361-011-0272-z) contains supplementary material, which is available to authorized users.

Correspondence to: Sonja Hess; e-mail: shess@caltech.edu research as their fragmentation significantly differs from that of the corresponding even electron species. Hydrogen deficient radical species can be generated in the gas phase by numerous methods. For example, tandem ionization in which ions are irradiated with high energy electrons $(>10 \mathrm{eV})$ results in further ionization and formation of an $[\mathrm{M}+\mathrm{nH}]^{(\mathrm{n}+1)^{+\cdot}}$ species $[1,2]$. In addition, high energy collisions with molecular oxygen of protonated amino acids [3], multiply protonated peptides [4], and multiply proton- 
ated lysozyme $(n=7-17)$ [5], and also femtosecond laserinduced ionization/dissociation of protonated peptides [6] can be used for the generation of hydrogen deficient species. Other methods are based on chemical derivatization of peptides or proteins to introduce a labile bond, which can then be homolytically cleaved in CID or photodissociation to produce hydrogen deficient molecular ions [7-13]. Recently, a new method, based on corona discharge initiated electrochemical ionization, has been shown to generate hydrogen deficient species from even electron precursor ions complexed with $\mathrm{Fe}$ of the stainless steel spraying tip or with $\mathrm{Cu}$ (II) added to the analyte solution [14].

A frequently used method for generation of hydrogen deficient species is based on low energy CID of ternary metal complexes containing an auxiliary ligand (L) and the peptide or amino acid (M), [Metal(L)M $]^{\mathrm{n}+}[15-26]$. Under low energy CID, dissociation of the $[\operatorname{Metal}(\mathrm{L}) \mathrm{M}]^{\mathrm{n}+}$ complex is observed and the metal-auxiliary ligand system removes an electron from the departing peptide resulting in the generation of the hydrogen deficient species [18, 21, 27]. This method was introduced by Siu and coworkers [15] and since its inception several investigations examine the role and the effect of the auxiliary ligand [18-20, 22, 24, 27-30] and the metal ion used $[20,31]$ in the generation of the radical cations. Furthermore, the individual amino acids, the peptide amino acid composition, and the position of the basic or the aromatic amino acids have been examined to determine their effect on the formation of the peptide radical cations [15-17, 27, 30, 32]. These investigations revealed that the gas phase chemistry of these metal-auxiliary ligandpeptides (or amino acids) complexes is extremely dynamic and diverse and that the generation of peptide radical cations is highly dependent on the choice of the auxiliary ligand. By altering the structure of the auxiliary ligand, competing fragmentation channels, such as peptide fragmentation or elimination of the protonated peptide, can be reduced and therefore the yield of the desired redox reaction generating the peptide radical cations can be maximized $[18,22,24$, 27]. Furthermore, the metal ion used, the peptide composition and the presence of specific amino acids, Tyr, Trp, Arg, Lys, His in the polypeptide also play a significant role in the generation of these radical cations [15-17, 27, 30, 32]. It should be pointed out that regardless of the metal ion and the auxiliary ligand used, the presence of both a basic, Arg, His, Lys, and an aromatic Trp or Tyr amino acid residue facilitate the formation of the $[\mathrm{M}+\mathrm{nH}]^{(\mathrm{n}+1)+\cdot}$ species [15-20].

In addition to the investigations focusing on the generation of hydrogen deficient peptide radical cations, several reports have focused on their gas phase dissociation, mainly in CID [11, 21, 27-29, 32-42]. In the initial report of Siu and coworkers it has been demonstrated that CID of hydrogen deficient species exhibit different fragmentation patterns when compared to those obtained in CID of the even electron species [15].

The presence of distonic ions, in which the charge and the radical site are located in different atoms in the molecule, is believed to play a significant role in the fragmentation pathways of hydrogen deficient radical cations [15, 17, 34]. Furthermore, both radical driven and charge driven processes have been shown to be important in the dissociation of hydrogen deficient species [27, 32, 34, 40, 43]. By comparing the fragmentation of $\mathrm{M}^{+},[\mathrm{M}+\mathrm{H}]^{2+\cdot}$ and $[\mathrm{M}-2 \mathrm{H}]^{-}$species [36], it was shown that charge remote radical driven fragmentation plays a significant role in the fragmentation of odd electron species and accounts for many side chain cleavages and backbone fragmentation, in agreement with previous reports [32]. While radical driven fragmentation favors side chain losses, either as neutral or radical losses, and dissociation of $\mathrm{C}_{\alpha}-\mathrm{C}$ bonds, charge driven fragmentation favors the formation of $y$ - and $[\mathrm{b}-\mathrm{H}]^{-}$-type product ions [27, 32, 40, 43]. In addition, radical-directed fragmentation leads to the formation of $c$ - and $z$-type product ions $[9,36,44]$.

Recently, CID fragmentation pathways of a series of arginine containing peptides featuring a well-defined initial location of the radical site were examined [40]. The peptide $\alpha$-radical cations were generated in an $\mathrm{MS}^{3}$ experiment by loss of a neutral side chain during CID of the $\mathrm{M}^{+\cdot}$ species, which was formed by in-source CID of $\left[\mathrm{Co}^{\mathrm{III}}(\text { salen}) \mathrm{M}\right]^{+}$ complexes. For arginine containing peptides, the dissociation was directed by radical driven processes. In contrast, the fragmentation of small $\alpha$-radical peptide cations formed by the loss of the arginine side chain was dominated by charge directed processes resulting in cleavage of the amide bonds. The authors suggested that for $\alpha$-radical cations of arginine containing peptides charge directed fragmentation is suppressed, because the proton is sequestered by the arginine. For $\alpha$-radical cations of small peptides lacking an arginine, the proton is mobile and therefore charge directed fragmentation is energetically and kinetically favorable. For larger peptides, lacking an arginine, radical-driven fragmentation is much more pronounced [40].

The role of the position of the basic amino acid residue, Arg, Lys, His, in the fragmentation of $\mathrm{M}^{+\cdot}$ precursor ions was also investigated [32]. It has been suggested that fragmentation reactions in CID of radical cations are determined by the competition between radical driven dissociation and charge directed dissociation. Furthermore, it was shown that radical driven side chain fragmentation reactions are influenced by the position of the basic amino acid and by the identity of the other amino acid residues present [32].

Radical migration is another important factor affecting the fragmentation of large hydrogen deficient species as demonstrated by Julian and coworkers [11]. Radical migration was also reported in CID of peptide radical cations of DRVGIHPF for which bond cleavages were remote from the initial location of the radical site suggesting that for this peptide the radical site is rather mobile [35].

While CID dissociation pathways of singly charged peptide radical cations $\mathrm{M}^{+}$, is a continuous area of research, very few reports investigated the dissociation of highly 
charged radical cations [21, 36, 44]. Doubly charged radical cations of several angiotensin derivatives were examined and it was suggested that these radical cations produce fragment ions similar to those observed in HECD, such as $z$ and $w$-type product ions [21]. CID of the $[\mathrm{M}+\mathrm{H}]^{2+}$. precursor ions of angiotensin III, RVYIHPF, displays fragmentation, which is characteristic of both the protonated and radical species, resulting in amino acid side chain losses and formation of $a$-, $y$ - and $z$-type product ions [36]. Furthermore, CID of $[\mathrm{M}+\mathrm{H}]^{2+\cdot}$ species, generated after photoactivation at $266 \mathrm{~nm}$ and collisional activation of peptides complexed with 5-iodo-2-(2-hydroxymethyl-18-crown-6)naphthoate, resulted in abundant side chain losses and preferential fragmentation at aromatic amino acid residues to produce mainly $a$-type product ions. The authors suggested that fragmentation of radical precursor cations is primarily controlled by radical rather than charge driven processes [44].

The several different fragmentation pathways observed between these reports [21, 36, 44] and the fact that less is known about the fragmentation pathways of highly charged hydrogen deficient radical cations motivated us to further explore their fragmentation behavior. We have investigated the fragmentation of singly, doubly and triply charged peptide radical cations in IRMPD and EID and compared the observed fragmentation pathways with those observed in CID.

Although dissociation in both IRMPD and CID is caused by vibrational excitation of the molecular ion and, therefore, they have many common characteristics, differences between these two dissociation techniques have been previously reported [45-48]. A main advantage of IRMPD versus CID is that product ions are generated in the ICR cell and therefore discriminations against product ions with low $\mathrm{m} / \mathrm{z}$ ratios, due to the time-of-flight effect, are eliminated. In addition, the product ions formed upon IRMPD are not subjected to the one-third rule, which is characteristic for CID performed in linear ion traps.

In contrast to CID and IRMPD, EID is an electron based dissociation technique. EID involves irradiation of the molecular ions with high energy electrons $(>10 \mathrm{eV})$. Depending on the electron energy several processes can occur such as electronic excitation and subsequent fragmentation [49-53], further ionization [1, 2], or further ionization followed by fragmentation of the molecular ions [53-55]. Such processes have been termed electron impact excitation of ions from organics [49-51], electron induced dissociation [52], electronic excitation dissociation [53, 55], and electron ionization dissociation [54]. A more generic term, electron induced dissociation was proposed by O'Hair and coworkers to account for these different processes. Here, we use the term electron induced dissociation (EID) to describe the fragmentation observed upon electron irradiation of the molecular ions with high energy $(>10 \mathrm{eV})$ electrons. EID is more often employed for the fragmentation of singly charged species, including protonated amino acids [56], protonated peptides $[54,56,57]$, protonated and sodiated betaine dimers [58], oligosaccharides [59], metalated fatty acids [60], oxo-centered trinuclear carboxylate-bridged iron complexes [61], deprotonated peptides [62], metabolites [63], and glycosaminoglycans [64]. More recently EID has also been applied for dissociation of multiply charged species in both positive [54, 65, 66] and negative [67] ion mode. In several of these investigations [56, 61, 63, 67] it has been demonstrated that EID provides complementary information to those obtained in CID.

The experiments presented here seek to expand our understanding of the gas-phase dissociation of hydrogen deficient radical species, investigate the effect of charge state on their dissociation outcome, and compare the fragmentation pathways observed following IRMPD, EID and CID. Singly, doubly, and triply charged hydrogen deficient radical cations were generated by CID of the $\left[\mathrm{Cu}^{(\mathrm{II})}(\text { terpy) })\right]^{2+}$, $\left[\mathrm{Cu}^{\text {(II) }} \text { (terpy) }(\mathrm{M}+\mathrm{H})\right]^{3+\cdot}$, and $\left[\mathrm{Cu}^{(\mathrm{II})}(\text { terpy })(\mathrm{M}+2 \mathrm{H})\right]^{4+\cdot}$ complexes, respectively. The corresponding radical species were isolated and then subjected to IRMPD, EID, and CID. Depending on charge state and amino acid composition of the investigated peptide, radical and/or charge driven fragmentation pathways were observed resulting in overall rich sequence information.

\section{Experimental}

\section{Sample Preparation}

The peptides angiotensin I (DRVYIHPFHL-OH), $\left[\mathrm{Ile}^{7}\right]$-angiotensin III (RVYIHPI-OH), adrenocorticotropic hormone fragment 1-10 (abbreviated as ACTH 1-10, (SYSMEHFRWG$\mathrm{OH}$ ), and neurotensin (pELYENKPRRPYIL-OH) were purchased from Sigma (St. Louis, MO, USA) and used without further purification. Copper(II)nitrate trihydrate and 2,2':6, $2^{\prime \prime}-$ terpyridine were obtained from Sigma. (2,2':6',2"-terpyridine) copper(II) nitrate monohydrate, ([Cu(II)(terpy) $\left.\left.\left(\mathrm{NO}_{3}\right)_{2}\right] \cdot \mathrm{H}_{2} \mathrm{O}\right)$, was synthesized as previously described [68], and dissolved in methanol (Sigma) before use. For the formation of $\left[\mathrm{Cu}^{(\mathrm{II})}\right.$ (terpy)M $]^{\mathrm{n}+}$ complexes, samples were prepared as follows; $5 \mu \mathrm{M}$ peptide and $8.5 \mu \mathrm{M}$ of $\left[\mathrm{Cu}(\mathrm{II})\left(\right.\right.$ terpy) $\left.\left(\mathrm{NO}_{3}\right)_{2}\right] \cdot \mathrm{H}_{2} \mathrm{O}$ in 50:50 methanol:water (Sigma) for neurotensin, $10 \mu \mathrm{M}$ peptide and $17 \mu \mathrm{M}$ of $\left[\mathrm{Cu}(\mathrm{II})(\right.$ terpy $\left.)\left(\mathrm{NO}_{3}\right)_{2}\right] \cdot \mathrm{H}_{2} \mathrm{O}$ in 50:50 methanol: water for angiotensin I, $10 \mu \mathrm{M}$ peptide and $17 \mu \mathrm{M}[\mathrm{Cu}$ (II) (terpy) $\left.\left(\mathrm{NO}_{3}\right)_{2}\right] \cdot \mathrm{H}_{2} \mathrm{O}$ in methanol for $[\mathrm{Ille}]$-angiotensin III. For ACTH 1-10, a higher peptide concentration, $20 \mu \mathrm{M}$, was required for detection of the $\left[\mathrm{Cu}^{(\mathrm{II})}(\text { terpy })(\mathrm{M}+\mathrm{nH})\right]^{(\mathrm{n}+2)}$. complex and $\left[\mathrm{Cu}(\mathrm{II})\left(\right.\right.$ terpy) $\left.\left(\mathrm{NO}_{3}\right)_{2}\right] \cdot \mathrm{H}_{2} \mathrm{O}$ was added to a final concentration of $19 \mu \mathrm{M}$ in 50:50 methanol:water.

\section{Mass Spectrometry and Data Analysis}

All experiments were performed on a 7 T LTQ FT-ICR Ultra mass spectrometer (Thermo Fisher Scientific, Bremen, Germany). Samples were directly infused in positive ion mode at a flow rate of $1 \mu \mathrm{L} / \mathrm{min}$, using a fused silica transfer tubing connected to a stainless steel spraying needle (New Objective, Woburn, MA). Electrospray ionization was achieved 
using a liquid junction. To maximize the signal of the $\left[\mathrm{Cu}^{(\mathrm{II})}\right.$ (terpy) $(\mathrm{M}+\mathrm{nH})]^{(\mathrm{n}+2)+\cdot}$ complexes, ESI source parameters were carefully tuned. Typical values were: spray voltage, 2.50 $3.00 \mathrm{kV}$; capillary temperature, $200-240{ }^{\circ} \mathrm{C}$; capillary voltage, 80-140 V, and tube lens offset voltage, 95-150 V.

Peptide radical cations were formed from the corresponding $\left[\mathrm{Cu}^{(\mathrm{II})}(\text { terpy })(\mathrm{M}+\mathrm{nH})\right]^{(\mathrm{n}+2)+\cdot}$ complexes after isolation of the latter in the linear ion trap followed by CID. CID was performed in the linear ion trap with helium as collision gas. Collision energies were optimized to maximize the abundance of the radical product ions. These radical ions were then isolated in the linear ion trap, with an isolation window of 4$5 \mathrm{Da}$, and either subjected to CID or transferred into the ICR cell for IRMPD and EID experiments. The automatic gain control (AGC) target value was set at $1 \times 10^{4}$ ions for CID experiments and at $2-5 \times 10^{5}$ ions for IRMPD and EID. The maximum ion injection times were $150 \mathrm{~ms}$ for CID, and 1000 $2000 \mathrm{~ms}$ for IRMPD and EID. The collision energy, the irradiation times, the laser power and the cathode voltages were adjusted for each radical precursor ion to achieve optimal fragmentation. CID was carried out with a normalized collision energy of $12 \%-30 \%$ and $30 \mathrm{~ms}$ activation time. The resulting product ions were transferred into the ICR cell for accurate mass measurement analyses. We note here, that following CID some product ions, detected at low $\mathrm{m} / \mathrm{z}$ ratios in the linear ion trap, were not efficiently transferred in the ICR cell due to the time-of-flight effect, therefore accurate mass measurements of these product ions were not feasible. When applicable, their $\mathrm{m} / \mathrm{z}$ ratios were compared to those obtained in $\mathrm{MS}^{3}$ IRMPD and assignments were made.

IRMPD experiments were performed with a continuous $20 \mathrm{~W}, 10.6 \mu \mathrm{m}, \mathrm{CO}_{2}$ laser (Synrad, Mukilteo, WA, USA) at $60 \%-90 \%$ laser power and photon irradiation times of 30 $150 \mathrm{~ms}$. For doubly charged neurotensin precursor ions, a higher irradiation time of $250 \mathrm{~ms}$ was required for efficient fragmentation. EID experiments were carried out with an indirectly heated dispenser cathode (Heatwave, Watsonville, CA, USA) at a cathode potential of $-14.2 \mathrm{~V}$ to $-21.2 \mathrm{~V}$ and irradiation time of $50-100 \mathrm{~ms}$.

All spectra were acquired with Tune Plus (ver. 2.2, Thermo Fisher Scientific) using a resolution of 25,000 or 50,000 at $\mathrm{m} / \mathrm{z}$ 400. Data processing was performed with Qual Browser analysis software (ver. 2.0.7, Thermo Fisher Scientific). Product ion spectra were interpreted with the aid of Fragmentor 1.2.2 (http://www.faculty.ucr.edu/ ryanj/fragmentor.html) and the MS Product function (http://prospector.ucsf.edu/prospector/ cgi-bin/msform.cgi?form=msproduct) in Protein Prospector. Only peak assignments with a mass accuracy better than $10 \mathrm{ppm}$ were accepted.

\section{Results and Discussion}

An overview of the experiment is shown in Scheme 1. Singly charged $\mathrm{M}^{+\cdot}$ species of angiotensin I, [Ile $]$-angiotensin III and ACTH 1-10 were generated by CID of [Cu ${ }^{\text {(II) }}$ (terpy)M $]^{2+\bullet}$ complexes of the corresponding peptide. Doubly

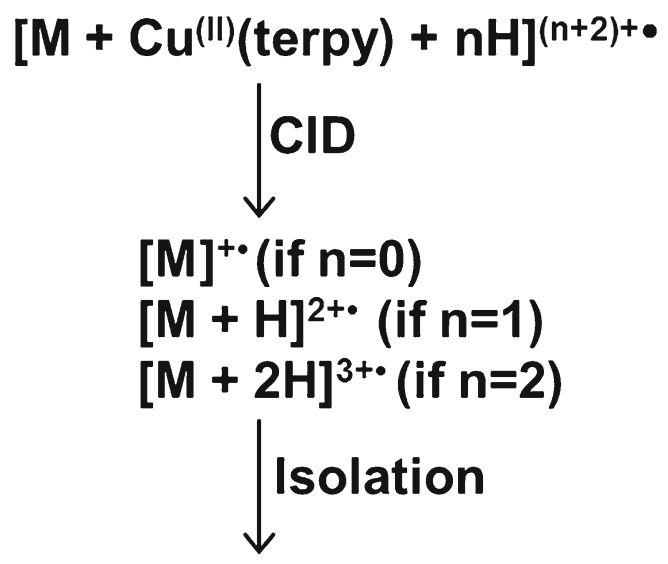

\section{IRMPD, EID or CID}

Scheme 1. Experimental Outline

charged $[\mathrm{M}+\mathrm{H}]^{2+\cdot}$ species of angiotensin I, $\left[\mathrm{Ile}^{7}\right]$-angiotensin III, ACTH 1-10 and neurotensin were generated by CID of $\left[\mathrm{Cu}^{(\mathrm{II})} \text { (terpy) }(\mathrm{M}+\mathrm{H})\right]^{3+\cdot}$ complexes of the corresponding peptides. Triply charged $[\mathrm{M}+2 \mathrm{H}]^{3+\cdot}$ species of angiotensin I and neurotensin were generated by $\mathrm{CID}$ of the $\left[\mathrm{Cu}^{(\mathrm{III})}\right.$ (terpy) $(\mathrm{M}+2 \mathrm{H})]^{4+\cdot}$ complexes. The resulting peptide radical cations were isolated and subjected to MS ${ }^{3}$ IRMPD, EID, and CID. For $\left[\mathrm{Ile}^{7}\right]$-angiotensin III and ACTH 1-10, the quadruply charged $\left[\mathrm{Cu}^{\text {(II) }} \text { (terpy) }(\mathrm{M}+2 \mathrm{H})\right]^{4+\cdot}$ complex was not detected and, thus, generation of the triply charged radical cations of these two peptides was not feasible.

All hydrogen deficient peptide cations examined here contain a tyrosine or tryptophan, which can easily form radical cations due to their low ionization energy. Furthermore, three of the examined peptides contain a histidine, which has also been shown to successfully generate radical cations [30]. We can therefore postulate that the unpaired electron is likely to be located at any of these three residues. It is important to note, that the exact location of the unpaired electron cannot be unambiguously determined because the binding mode of the peptide to $\left[\mathrm{Cu}^{\mathrm{II}}(\text { terpy })\right]^{2+\cdot}$ complex is not well defined, i.e., it is unclear which amino acid and which part of the amino acid binds to the $\left[\mathrm{Cu}^{\mathrm{II}}(\text { terpy) }]^{2+\cdot}\right.$ complex, and also radical migration has been shown to commonly occur in large hydrogen deficient peptides [11, 35, 40, 42, 69].

MS $^{3}$ IRMPD, EID, and CID fragmentation summary of the examined peptides is displayed in Schemes 2, 3, 4 and 5. Complete lists of all assigned product ions with their relative abundances are given in Supplemental Data in Tables S1-S27. Amino acid side chain losses are summarized in Tables S28-S39. CID was performed for comparison and a detailed discussion is given in Supplemental Data.

\section{$\mathrm{MS}^{3}$ IRMPD of Angiotensin I}

\section{Singly Charged Radical Cations $\mathrm{M}^{+}$}

$\mathrm{MS}^{3}$ IRMPD of angiotensin I resulted in $\mathrm{CO}_{2}$ loss, formation of $a$-type product ions and amino acid side chain 


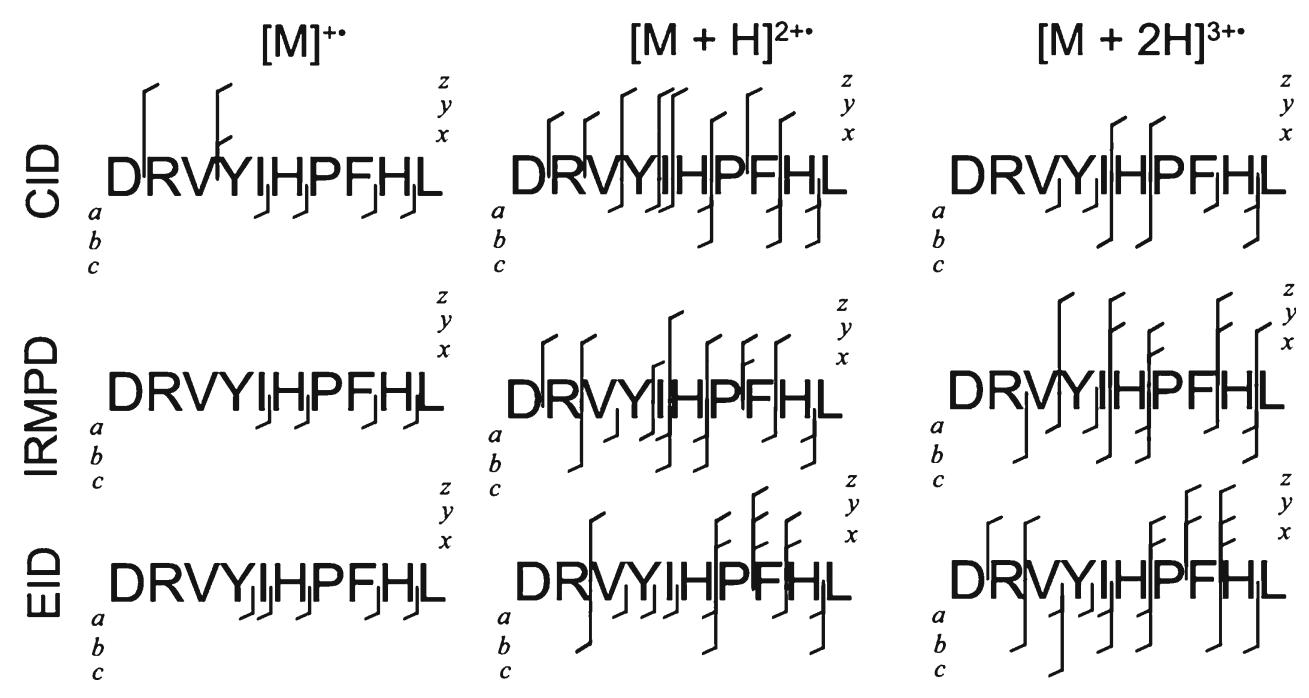

Scheme 2. CID, IRMPD and EID fragmentation summary ${ }^{\mathrm{a}}$ of radical cations of angiotensin I. ${ }^{\text {a }}$ Backbone product ions exhibiting one amino acid side chain loss are also included if their relative abundance was $\geq 5 \%$ for CID and IRMPD and $\geq 0.5 \%$ for EID

losses from the radical precursor ions (Figures 1a and 2a). Formation of $a_{9}$ and $a_{6}$ product ions, resulting from cleavages next to the two histidine residues was abundant (Figure 2a). Enhanced cleavage at aromatic residues was also observed in CID of the same species (Figure S1) and is in accordance with previous reports [44, 70, 71]. In the IRMPD spectrum, the $a_{5}$ and $a_{6}$ product ions were observed as $\left[a_{5}-\mathrm{H}\right]^{+\cdot}$ and $\left[a_{6}-\mathrm{H}\right]^{+{ }^{*}}$. Closer inspection of the monoisotopic distribution revealed that the $a_{6}$ product ion was a mixture of even and odd electron species, $a_{6} /\left[a_{6}-\mathrm{H}\right]^{+\cdot}$, whereas the $a_{5}$ product ion was detected solely as an odd electron species, $\left[a_{5}-\mathrm{H}\right]^{+\bullet}$. Similar trends were observed for

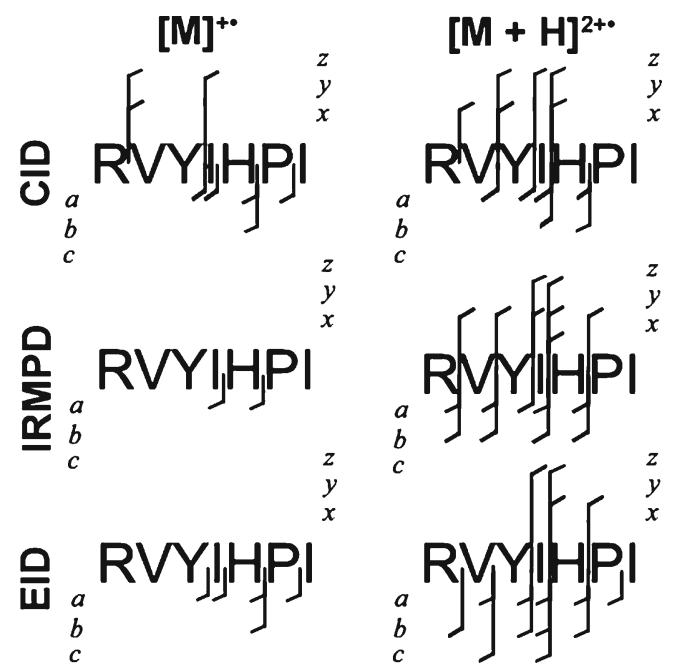

Scheme 3. CID, IRMPD and EID fragmentation summary ${ }^{\mathrm{a}}$ of radical cations of $\left[\mathrm{Ile}^{7}\right]$-angiotensin III. ${ }^{\mathrm{a}}$ Backbone product ions exhibiting one amino acid side chain loss are also included if their relative abundance was $\geq 5 \%$ for CID and IRMPD and $\geq 0.5 \%$ for EID the $a_{6}-\mathrm{CO}_{2}$ product ion, which was detected as a mixture of $a_{6}-\mathrm{CO}_{2}$ and $\left[a_{6}-\mathrm{H}-\mathrm{CO}_{2}\right]^{+\cdot}$. Formation of $[a-\mathrm{H}]^{+\cdot}$ type product ions has been previously observed in CID [40] and SID [35] spectra of hydrogen deficient peptide radical cations. In our CID spectrum of the singly charged radical cations of angiotensin I, the $a$-type product ions were detected as even electron species. Furthermore, formation of $z_{7}, z_{9}{ }^{*}, x_{7}$, arginine $\left(\mathrm{C}_{4} \mathrm{H}_{9} \mathrm{~N}_{3} 99.0796 \mathrm{Da}\right)$, and isoleucine $\left(\mathrm{C}_{2} \mathrm{H}_{5}\right.$. 29.0392 Da) side chain losses were present only in CID but were detected with low intensities.

Doubly Charged Radical Cations $[\mathrm{M}+\mathrm{H}]^{2+\cdot}$

$\mathrm{MS}^{3}$ IRMPD of the $[\mathrm{M}+\mathrm{H}]^{2+\cdot}$ precursor ions of angiotensin I (Figures $1 \mathrm{~b}$ and $2 \mathrm{a}$, Scheme 2) resulted in additional

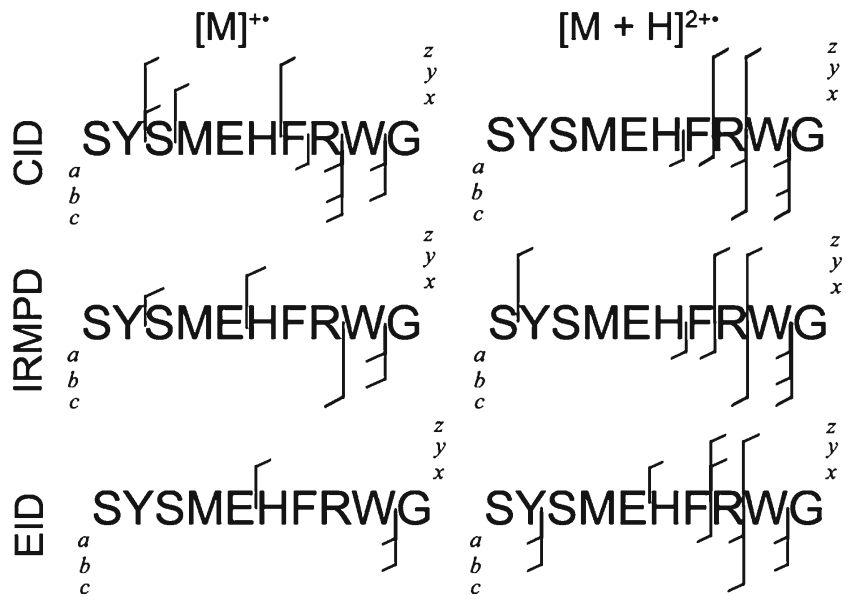

Scheme 4. CID, IRMPD and EID fragmentation summary ${ }^{\mathrm{a}}$ of radical cations of $\mathrm{ACTH} 1-10{ }^{\mathrm{a}}$ Backbone product ions exhibiting one amino acid side chain loss are also included if their relative abundance was $\geq 5 \%$ for CID and IRMPD and $\geq 0.5 \%$ for EID 

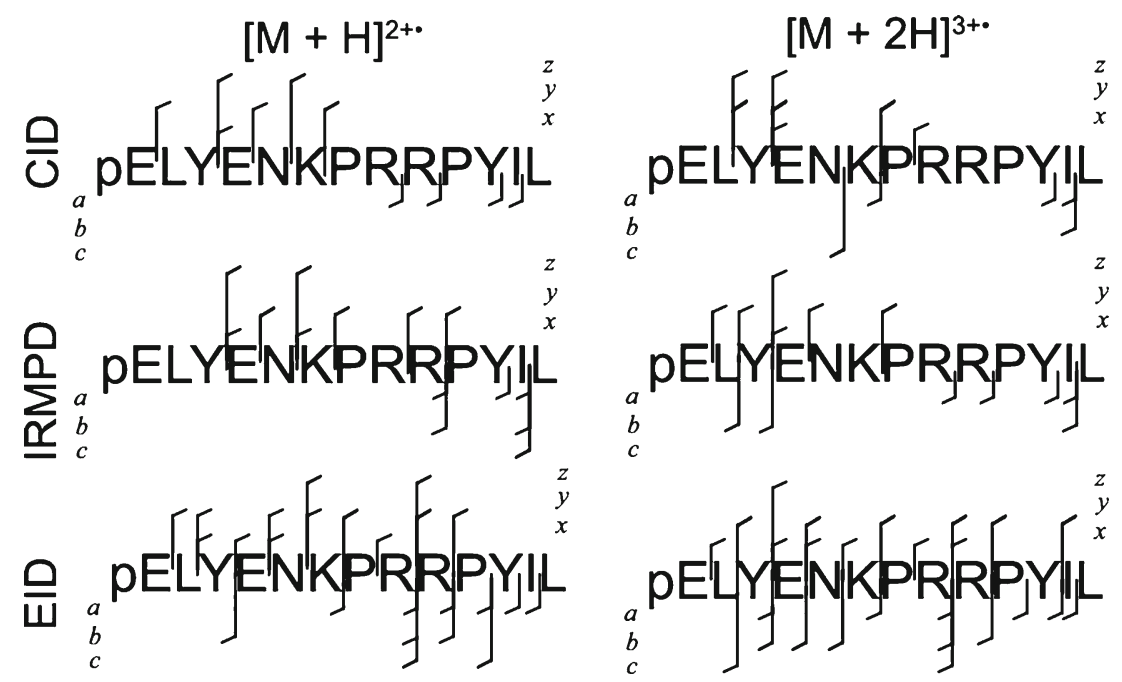

Scheme 5. CID, IRMPD and EID fragmentation summary ${ }^{\mathrm{a}}$ of radical cations of neurotensin. ${ }^{\mathrm{a}}$ Backbone product ions exhibiting one amino acid side chain loss are also included if their relative abundance was $\geq 5 \%$ for CID and IRMPD and $\geq 0.5 \%$ for EID

fragmentation pathways, which were not observed for the singly charged radical precursor ions. These include, mainly, formation of $b$-, $y$-, and $x$ - type product ions. Side chain loss from aspartic acid $(\mathrm{COOH}, 44.9976 \mathrm{Da})$ observed from the $b$-type product ions was also present. Loss of $\mathrm{CO}_{2}$ (43.9898 Da) and the majority of amino acid side chain losses were common for both charge states, although these were more pronounced for the doubly charged precursor ions. A series of $a$-type product ions, detected with high yields, was present in the spectrum. All $a$-type product ions, detected for the singly charged species, were also present in the doubly charged counterpart, whereas the $a_{3}$ and $a_{4}$ product ions were only observed for the doubly charged radical cations. The most abundant backbone product ions were $a_{9}$ and $y_{8}$ ions (Figure 2a). The former is due to cleavage next to histidine and it was also the most abundant backbone product ion in IRMPD of the singly charged radical precursor ions. The $y_{8}$ was also observed in IRMPD of the doubly charged even electron precursor ions (data not shown) but represented a minor product ion, suggesting that radical driven dissociation also contributed to the formation of this product ion.

Although, the $\mathrm{MS}^{3}$ IRMPD and CID spectra of the doubly charged radical cations of angiotensin showed several similarities, such as formation of abundant $a$-type product ions, side chain losses from tyrosine and aspartic acid and $\mathrm{CO}_{2}$ loss, they were not identical. For instance, some backbone product ions were unique for each spectrum (Scheme 2). In addition, several $z$-type product ions were detected in CID, whereas in IRMPD C-terminal $x$-type product ions were present. Formation of odd electron $z$-type product ions has been previously observed in $\mathrm{MS}^{3} \mathrm{CID}$ of hydrogen deficient radical cations and it was suggested that odd electron $z$-type product ions can be formed from unstable $\left[\mathrm{x}_{\mathrm{n}}+\mathrm{H}\right]^{+\cdot}$ product ions by loss of isocyanic acid through a radical driven process [44]. Furthermore, formation of $x$-type product ions from radical cations has been recently discussed in detail [40]. In our experiments, although $z$ - and $x$-type product ions were present they were detected with lower intensities when compared to $a-, b$ - and $y$-type product ions.

\section{Triply Charged Radical Cations $[\mathrm{M}+2 \mathrm{H}]^{3+\cdot}$}

As shown in Figures 1c and 2a, $M^{3}$ IRMPD of triply charged radical cations of angiotensin I resulted in extensive fragmentation. Similar to the IRMPD spectra of the singly and doubly charged radical cations, $\mathrm{CO}_{2}$ loss corresponded to the most abundant product ion. For the triply charged species tyrosine (106.042 Da) side chain loss was dominant whereas for the singly and doubly charged species, this loss represented a minor fragmentation pathway. Loss of $\mathrm{COOH}^{\circ}$ from aspartic acid, observed from the $a$ - and $b$-type product ions, was also prevalent for the triply charged radical cations. Almost all backbone product ions containing aspartic acid exhibited loss of $44.9977 \mathrm{Da}$ indicating cleavage of $\mathrm{COOH}^{\circ}$ [abbreviated as $\left.-45(\mathrm{D})\right]$. A wide range of $a$-, $b$-, $y$, and $z$-type product ions was also observed. The vast majority of these backbone product ions were detected with high relative intensities as shown in Figure 2a. The $y_{1}$, $y_{2}, y_{4}$, and $x_{4}-\mathrm{CO}_{2}$ were also present following IRMPD of the triply charged even electron precursor ions (data not shown). The $a_{3}, a_{8}, z_{2}{ }^{\cdot}-56$ (I) and $\mathrm{z}_{5}{ }^{\cdot}$ were only observed from the radical species and they correspond to cleavages next to tyrosine, phenylalanine and histidine residues. The $b$-type product ions, detected as $b_{n}-45$ (D) $(n=2,5,6,9)$ for the radical precursor cations, were all present in the spectrum of the even electron species, and did not exhibit $\mathrm{COOH}^{\prime}$ loss, as expected. 

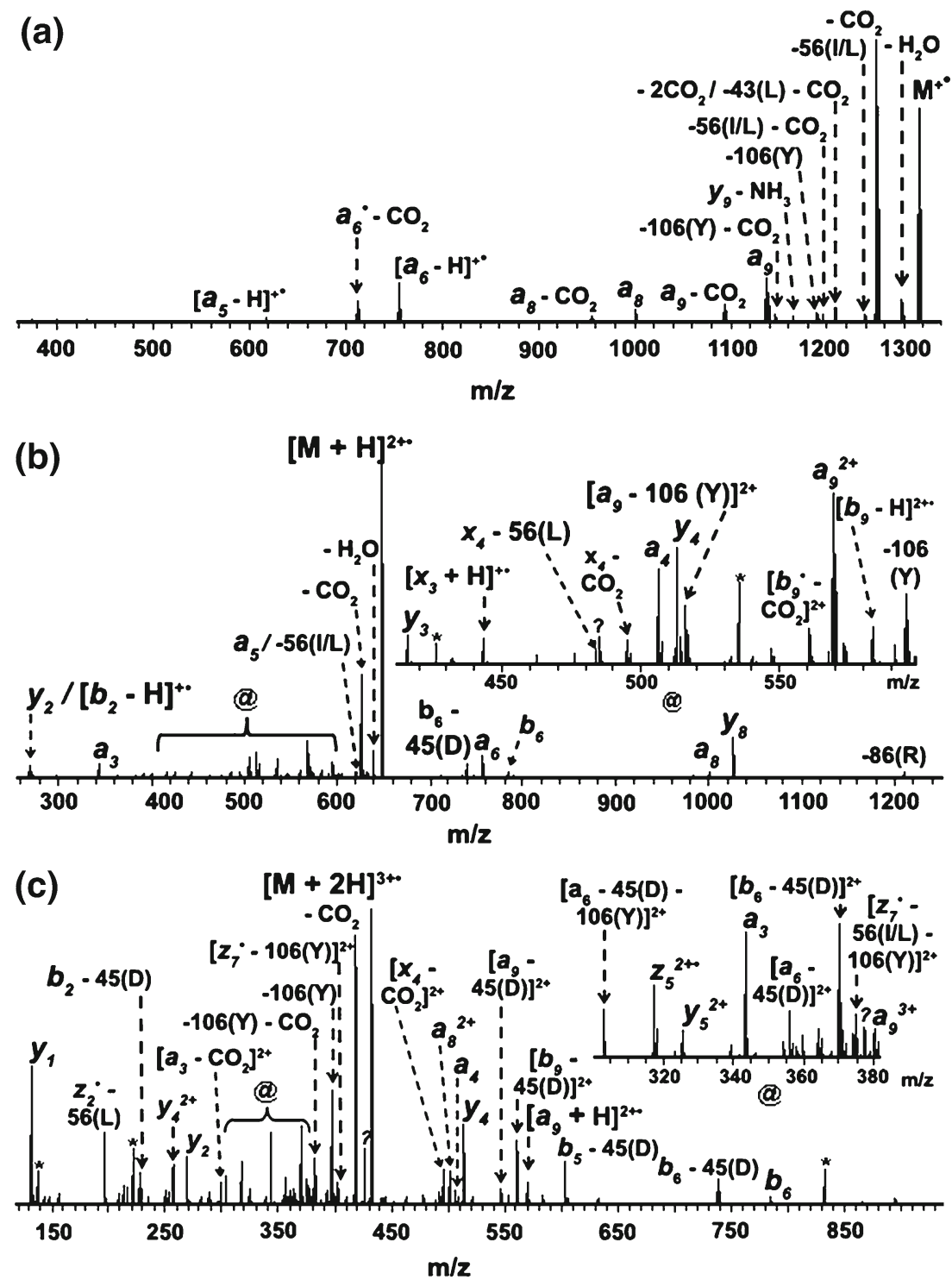


type product ions were observed for the singly charged radical cations, whereas for the doubly and triply charged radical species $a-, b$-, $y$ - and $x$-type product ions were present. Amino acid side chain and $\mathrm{CO}_{2}$ losses were detected for all charge states. Only the major peaks are labeled in the Figure. A complete list of all observed product ions is given in Supplemental data, Tables S10-S12. * = noise peak, ? = unidentified product ions

Despite the fact that a wide range of product ions i.e., $a-, b-, y-, x$-, and $z$-type was observed in IRMPD of the doubly and triply charged species, some backbone product ions were only observed for either the doubly or triply charged radical species (Figure 2a, and Scheme 2). In addition, the relative intensities of common product ions significantly differed between the two spectra as illustrated in Figure 2a. For instance, the $a_{3}$ product ion was detected with a relative intensity of $\sim 4 \%$ and $\sim 25 \%$ for the doubly and triply charged species, respectively. The $\mathrm{MS}^{3} \mathrm{CID}$ and IRMPD spectra of the triply charged radical cations of angiotensin I shared some commonalities, including $\mathrm{CO}_{2}$ loss, tyrosine side chain loss, abundant formation of $y_{4}$ product ion and extensive $\mathrm{COOH}$ loss from aspartic acid. Nevertheless several product ions were only detected in IRMPD (Scheme 2). All product ions present in CID were also detected in IRMPD.

\section{$\mathrm{MS}^{3}$ EID of Angiotensin I}

\section{Singly Charged Radical Cations $M^{+}$}

In contrast to IRMPD and CID spectra, following MS ${ }^{3}$ EID of angiotensin I (Figures $2 b$ and $3 a$ ) amino acid side chain 

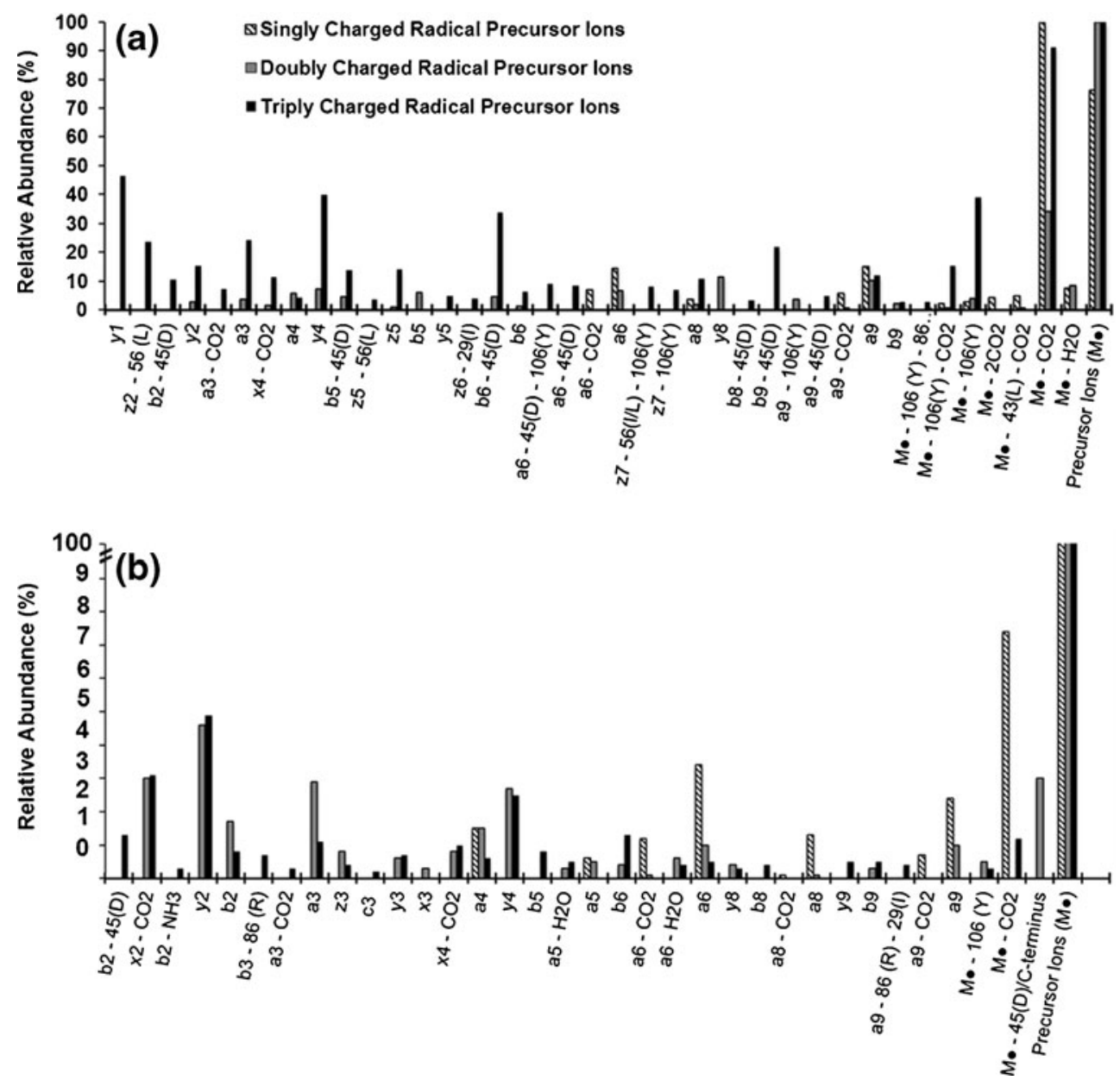

Figure 2. Product ion abundance distribution obtained in $\mathrm{MS}^{3}$ (a) IRMPD and (b) EID of the singly, doubly and triply charged radical cations of angiotensin I. Only the most abundant product ions are displayed in the Figure. All backbone product ions are shown in Scheme 2 and a complete list of all observed product ions is given in Supplemental data (Tables S10-S12 and S19-S21). For simplicity the charge state of the product ions and hydrogen atom losses are not shown

losses were absent. The only small neutral loss observed corresponded to $\mathrm{CO}_{2}$ loss. The spectrum was dominated by formation of $a$-type product ions, as it was observed in CID and IRMPD. The $a_{6}$ and $a_{9}$ product ions were the most intense backbone product ions (Figure $2 \mathrm{~b}$ ) and correspond to cleavage of the $\mathrm{C}_{\alpha}-\mathrm{C}$ bond of histidine residues at position six and nine, respectively. One doubly charged product ion corresponding to $\left[\mathrm{M}-\mathrm{CO}_{2}\right]^{2+\cdot}$ (notation is to indicate that the molecule carries two charges and two unpaired electrons) species was observed. Formation of this doubly charged species is due to electron ionization (of the $\mathrm{M}^{+\cdot}$ precursor ions) caused by the high energy electrons $(>10 \mathrm{eV})$ employed in EID. Our observations are in agreement with previous reports in which it was demonstrated that protonated polypeptides can increase their charge state after irradiation with high energy electrons $(\geq 10 \mathrm{eV})$ due to further ionization of the precursor ions [1, 53-55]. Analogous results, formation of an electron-ionized fragment ion, $\left[\mathrm{M}-\mathrm{CO}_{2}+\mathrm{H}\right]^{2+}$ were recently reported in EID of $[\mathrm{M}+\mathrm{H}]^{+}$precursor ions of RPPFSFFR and KRTLRR [57]. We note that the nature of the precursor ions used in our experiments is a hydrogen deficient odd electron species, whereas the precursor ions used in the aforementioned reports is an even electron species $[1,53,55$, 57]. Nevertheless, in both cases a doubly charged species is formed from a singly protonated precursor ions, suggesting that both odd and even electron precursor ions undergo further ionization upon irradiation with high energy electrons.

\section{Doubly Charged Radical Cations $[\mathrm{M}+\mathrm{H}]^{2+}$}

Following $\mathrm{MS}^{3}$ EID of the doubly charged radical precursor ions of angiotensin I, (Figures $2 b$ and $3 b$, Scheme 2), a large number of backbone product ions including $a$-, $b$-, $y$-, and $x$-type were detected. Enhanced cleavage next to aromatic residues is indicated through the formation of abundant $a_{3}$, $a_{4}$ and $x_{2}-\mathrm{CO}_{2}$ product ions (Figure 2b). Charge driven fragmentation, was also favorable for this charge state yielding intense $b_{2}, y_{2}$, and $y_{4}$ product ions. The triply charged electron-ionized species $[\mathrm{M}+\mathrm{H}]^{3+\cdot \cdot}$, at $m / z=$ 432.2284 (Figure 3b), was also abundant. As discussed 


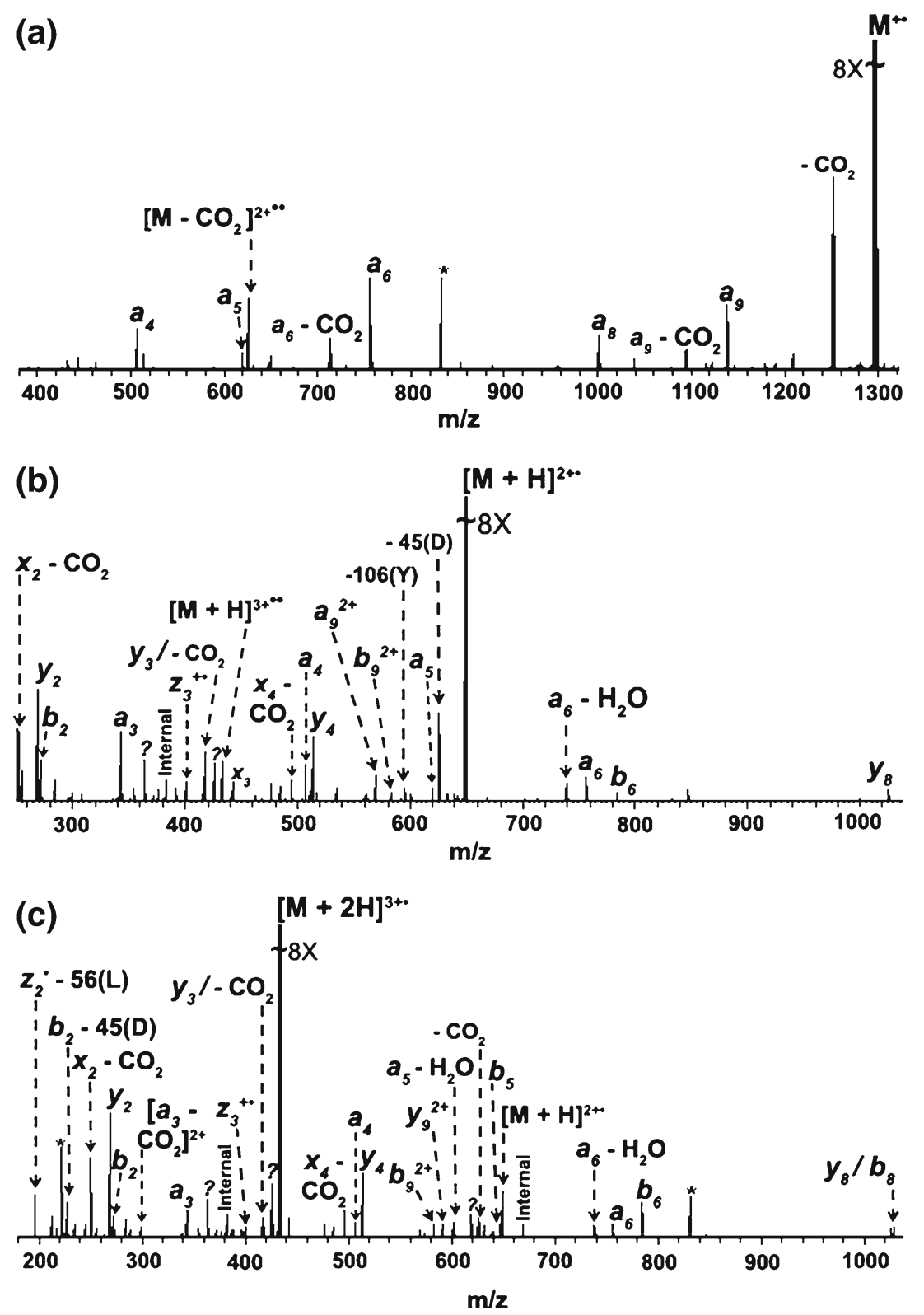

Figure 3. MS $^{3}$ EID of (a) singly, (b) doubly and (c) triply charged radical cations of angiotensin I, DRVYIHPFHL. Solely a- type product ions and $\mathrm{CO}_{2}$ loss were detected in the spectrum of the singly charged radical cations. For the doubly and triply charged counterparts, a wide range of product ions including $a-, b-, y-, z$ - and $x$-type was detected. A complete list of all generated product ions is given in Supplemental data, Tables S19-S21. ${ }^{*}=$ noise peak, ? = unidentified product ions

above, the formation of this species is due to further ionization of the $[\mathrm{M}+\mathrm{H}]^{2+\cdot}$ precursor ions. Amino acid side chain losses were less extensive in EID, compared with the results obtained in CID and IRMPD. Furthermore, few product ions were unique for each dissociation technique, but for all three techniques both radical and charge driven processes contributed to the fragmentation outcome of the doubly charged radical cations.

\section{Triply Charged Radical Cations $[\mathrm{M}+2 \mathrm{H}]^{3+\cdot}$}

$\mathrm{MS}^{3}$ EID of the triply charged radical cations of angiotensin I (Figure $3 \mathrm{c}$ and Scheme 2) yielded a large number of backbone product ions. Even though cleavage next to aromatic amino acids did not dominate the spectrum, product ions, i.e., $a_{3}$ and $\mathrm{z}_{2}{ }^{\cdot}-56(\mathrm{~L})$, corresponding to such cleavages were present in relatively high yields (Figure $2 b$ ). In addition, side chain losses and formation of several $a-, z-$, and $x$ - product ions were detected. Product ions derived from charge driven dissociation, i.e., $b$ - and $y$-type, were abundant, with the $y_{2}$ representing the most abundant product ion. Similar to the results obtained for the other charge states, side chain, and neutral losses were less abundant compared with the results observed in $\mathrm{MS}^{3}$ IRMPD. In addition, as illustrated in Scheme 2, several backbone product ions were present only in EID or IRMPD. 
$\mathrm{MS}^{3}$ EID of doubly and triply charged radical cations of angiotensin I resulted in similar fragmentation (Figure 2b), although some product ions were unique for each charge state (Scheme 2).

\section{$\mathrm{MS}^{3}$ IRMPD of [lle $\left.{ }^{7}\right]$-Angiotensin III}

\section{Singly Charged Radical Cations $\mathrm{M}^{+}$}

Following IRMPD of [Ile $]$-Angiotensin III, side chain loss from tyrosine (106.042 Da), $\mathrm{CO}_{2}$ loss, and formation of the $a_{5}$ product ion, resulting from cleavage at the $\mathrm{C}_{\alpha}-\mathrm{C}$ bond of the histidine residue, were the predominant fragmentation pathways (Figure 4a). One additional backbone product ion, $a_{4}$, corresponding to cleavage at the N-terminal side of histidine was also present. These results are analogous to those observed in CID, although in CID more extensive backbone fragmentation and more side chain cleavages were observed (Figure S2).

\section{Doubly Charged Radical Cations $[\mathrm{M}+\mathrm{H}]^{2+\cdot}$}

We next investigated $\mathrm{MS}^{3}$ IRMPD of the $[\mathrm{M}+\mathrm{H}]^{2+}$ precursor ions of $\left[\mathrm{Ile}^{7}\right]$-angiotensin III (Figure $4 \mathrm{a}$ ). Similar to $\mathrm{MS}^{3}$ IRMPD of angiotensin I, MS ${ }^{3}$ IRMPD of the doubly charged ions resulted in the formation of $a-, b-, y_{-}, x-$, and $z$-type product ions. In addition, several $a$-type product ions, which were not observed for the singly charged radical cations, were detected for the doubly charged species. Interestingly, the $\mathrm{CO}_{2}$ loss, which was very abundant for the singly charged radical precursor ions, was not observed from the doubly protonated precursor ions. The major fragmentation pathways for the doubly charged species corresponded to the formation of $a_{2}, a_{3},\left[b_{4}-\mathrm{H}-86(\mathrm{R})\right]$,


Figure 4. Product ion abundance distribution obtained in $\mathrm{MS}^{3}$ (a) IRMPD and (b) EID of the radical cations of [lle $\mathrm{e}^{7}$-angiotensin III. Only the most intense product ions are displayed in the Figure. All backbone product ions are shown in Scheme 3 and a complete list of all observed product ions is given in Supplemental data (Tables S13-S14 and S22-23). For simplicity the charge state of the product ions and hydrogen atom losses are not shown 
$\left[b_{5}-\mathrm{H}-86(\mathrm{R})\right]$, and $y_{2}$ product ions and cleavages of arginine $\left(\mathrm{C}_{3} \mathrm{H}_{8} \mathrm{~N}_{3} \cdot 86.0718 \mathrm{Da}\right)$ and tyrosine $\left(\mathrm{C}_{7} \mathrm{H}_{6} \mathrm{O}^{\cdot}\right.$ 106.0418 Da) side chains (Figure 4a). The $a_{2}$ and $a_{3}$ product ions result from cleavages next to tyrosine. The two most abundant product ions $\left[b_{5}-\mathrm{H}-86(\mathrm{R})\right]$ and $y_{2}$ are complementary and correspond to cleavage between histidine and proline. Cleavage at N-terminal proline is pronounced in vibrational excitation of even electron protonated peptides containing a proline. In fact, following IRMPD of the even electron species (data not shown) the dominant product ions were the $b_{5}$ and $y_{2}$. As expected, the arginine side chain loss $(86 \mathrm{Da})$ from the $b_{5}$ product ion was not observed in IRMPD of the even electron species. These results indicate that formation of the $y_{2}$ product ion was not initiated by a radical process, whereas the formation of the $\left[b_{5}-\mathrm{H}-86(\mathrm{R})\right]$ was initiated by both, radical and charge processes. The former process contributed to the arginine side chain loss and the latter contributed to the cleavage N-terminal to proline. In agreement with these observations, IRMPD of the even electron species (data not shown) resulted in the formation of $b_{4}$, whereas IRMPD of the odd electron precursor ions resulted in the formation of $\left[b_{4}-\mathrm{H}-86(\mathrm{R})\right]$.

Comparing the CID and IRMPD spectra of the $[\mathrm{M}+\mathrm{H}]^{2+\cdot}$ precursors ions of $\left[\mathrm{Ile}^{7}\right]$-angiotensin III, several backbone product ions detected in IRMPD were absent in CID (Scheme 3), and relative intensities of common product ions were different (Figures 4a and S2). For instance, following CID, the base peak corresponded to tyrosine side chain loss, whereas in IRMPD the base peak was the $\left[b_{5}-\mathrm{H}-86(\mathrm{R})\right]$ ion. Furthermore, amino acid side chain losses from the product ions were more pronounced in IRMPD. This behavior is not surprising because these cleavages are a result of secondary fragmentation (resulting from multiple bond cleavages). In IRMPD, primary product ions can further absorb IR photons and thereby become further activated to yield secondary product ions. In fact, for the majority of the radical cations examined here, secondary product ions were more abundant in the IRMPD spectra.

\section{$\mathrm{MS}^{3}$ EID of [lle $]$-Angiotensin III}

\section{Singly Charged Radical Cations $M^{+}$}

Following $\mathrm{MS}^{3}$ EID of the singly charged species of $\left[\mathrm{Ile}^{7}\right]$ angiotensin III (Figure 4b), several fragmentation pathways were similar to those observed in $\mathrm{MS}^{3}$ IRMPD and CID. These pathways include formation of $a$-type product ions, $\mathrm{CO}_{2}$ loss from the radical precursor ions and extensive tyrosine side chain loss (106.042 Da). Formation of $a_{5}$ product ion, due to cleavage at the C-terminal side of histidine, was the dominant dissociation pathway. In addition, $a_{3}, a_{4}, a_{6}$, and a low intensity $b_{5}$ product were also detected. The extent of backbone fragmentation in EID was comparable to CID, although EID was more selective in forming $a$-type product ions (Scheme 3). Compared with IRMPD, EID resulted in more backbone product ions (Scheme 3).

\section{Doubly Charged Radical Cations $[M+H]^{2+}$.}

Similar fragmentation patterns to those obtained in $\mathrm{MS}^{3}$ IRMPD and CID were observed following $\mathrm{MS}^{3} \mathrm{EID}$ of the $[\mathrm{M}+\mathrm{H}]^{2+\cdot}$ of $\left[\mathrm{Ile}^{7}\right]$-angiotensin III (Figure $4 \mathrm{~b}$ ). These included formation of $a$-, $b$-, $y$-, and $z$-type product ions and side chain losses from the precursor and product ions. These side chain losses were more dominant in IRMPD. Favorable cleavages next to tyrosine to produce abundant $a_{2}$ and $a_{3}$ and tyrosine side chain losses were also in agreement with the results obtained in CID and IRMPD. The $y_{2}$ product ion, corresponding to cleavage N-terminally to proline, was also dominant. Formation of $c$-type product ions, $c_{2}$ and $c_{4}$, were only present in EID. Furthermore, as noted for angiotensin I, some backbone product ions were unique for each dissociation technique (Scheme 3).

\section{$\mathrm{MS}^{3}$ IRMPD of ACTH 1-10}

\section{Singly Charged Radical Cations $M^{+}$}

MS $^{3}$ IRMPD of ACTH 1-10 (Figures 5a and 6a) yielded several product ions corresponding to small neutral losses, i.e., $\mathrm{H}_{2} \mathrm{O}$ and $\mathrm{CO}_{2}$, and amino acid side chain losses. Most of these amino acid side chain losses were also detected following $\mathrm{MS}^{3}$ CID (Figure S3). In terms of backbone fragmentation, this was less extensive and less abundant in IRMPD. All observed backbone product ions corresponded to cleavages next to tyrosine, histidine and tryprophan (Scheme 4). The most abundant backbone product ions were the $\left[a_{9}-\mathrm{H}_{2} \mathrm{O}\right]$ and $\left[b_{9}-\mathrm{H}_{2} \mathrm{O}\right]$ due to cleavage $\mathrm{C}$-terminal to tryptophan (Figure 6a). In addition, the $a_{9}$ and $b_{9}$ product ions exhibited extensive amino acid side chain losses.

In contrast to the results obtained in IRMPD of the radical cations of angiotensin I and $\left[\mathrm{Ile}^{7}\right]$-angiotensin III in which almost exclusive formation of $a$-type backbone product ions was observed, IRMPD of ACTH 1-10 produced $a-, b-, c-, y$-, and $x$-type product ions. These observations are analogous to those obtained in $\mathrm{MS}^{3} \mathrm{CID}$ of the same species (Scheme 4). Differences in the fragmentation behavior between the two angiotensin derivatives and ACTH 1-10 can be attributed to differences in amino acid composition and charge location. It has been shown that fragmentation channels for radical cations of GXR (where X represents any of the 20 naturally occurring amino acids) are not identical and depend on the nature of the side chain of $X$ [34]. The authors suggested that the radical is located at different positions on the tripeptide and, thus, allows for a wide range of fragmentation channels [34]. Furthermore, it was suggested that fragmentation of peptide radical cations depends both on the nature and position of the residues in 


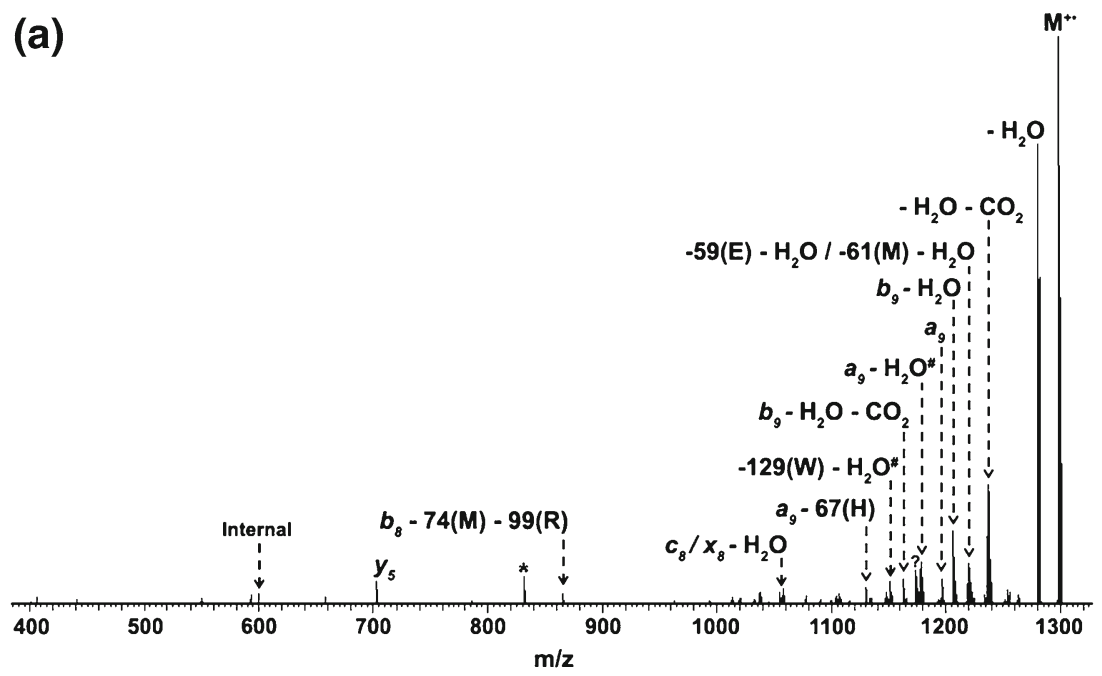

(b)

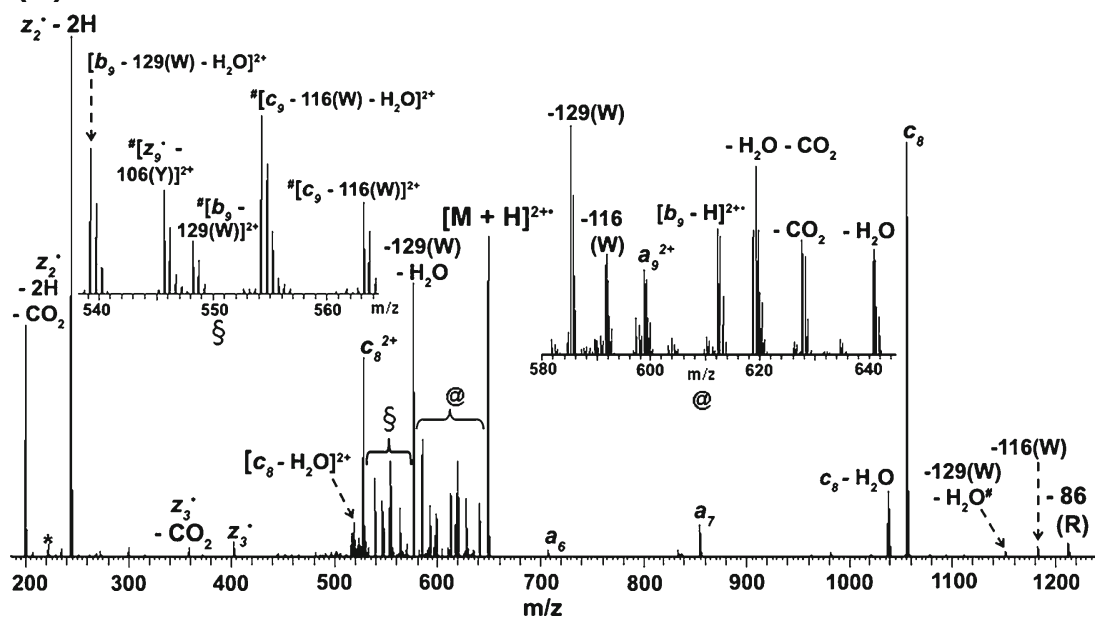

Figure 5. MS ${ }^{3}$ IRMPD of (a) singly and (b) doubly charged radical cations of ACTH 1-10, SYSMEHFRWG-OH. More extensive fragmentation was observed for the doubly charged radical precursor ions and cleavage at the $\mathrm{N}$-terminal side of tryptophan residue dominates the spectrum. Only the major peaks are labeled in the Figure. A complete list of all observed product ions is given in Supplemental data, Tables $\mathrm{S} 15$ and $\mathrm{S} 16 .{ }^{*}=$ noise peak, \# = more than one assignment possible based on $\mathrm{m} / \mathrm{z}$ ratio

the sequence [32] and it was also shown that dissociation of bradykinin analogues is different from the dissociation of angiotensin analogues [36]. Therefore, differences in the fragmentation behavior between the two angiotensin derivatives and ACTH 1-10 can be attributed to sequence differences. This can be further supported by the observation that for angiotensin I and $\left[\mathrm{Ile}^{7}\right]$-angiotensin III, which have similar amino acid composition, similar fragmentation pathways were observed.

In addition, for the two angiotensin derivatives the arginine is located at and next to the $\mathrm{N}$-terminus, whereas for ACTH 1-10 the arginine is closer to the C-terminus. It has been previously shown that fragmentation of singly charged radical cations featuring an arginine residue close to the N-terminus (and therefore having the charge localized at the N-terminus) results in facile formation of $a$-type product ions [36, 40, 70, 71]. For peptides featuring an arginine residue close to the $\mathrm{C}$-terminus, formation of a wide range of product ions including $a$-, $y$-, $x$-, and $z$-type product ions has been reported in the literature [16, 40]. Furthermore, the formation of $x$ - and $z$-type product ions from peptide radical cations in which the charge is localized on the C-terminus has been recently discussed in detail [40]. Similar to these reports, fragmentation of angiotensin I and $\left[\mathrm{Ile}^{7}\right]$-angiotensin III resulted in favorable formation of $a$-type product ions, whereas for ACTH 1-10 formation of $a-, b-, c-, y$-, and $x$-type product ions was observed.

\section{Doubly Charged Radical Cations $[\mathrm{M}+\mathrm{H}]^{2+}$.}

Analogous to the results obtained for the other peptides examined, more extensive fragmentation was observed for the doubly charged radical cations of ACTH 1-10 compared with the singly charged species (Figures $5 \mathrm{~b}$ and 6a, Scheme 4). Dominant fragmentation pathways were the formation of $\left[z_{2}-2 \mathrm{H}\right]$ and $c_{8}$ product ions, with the latter 

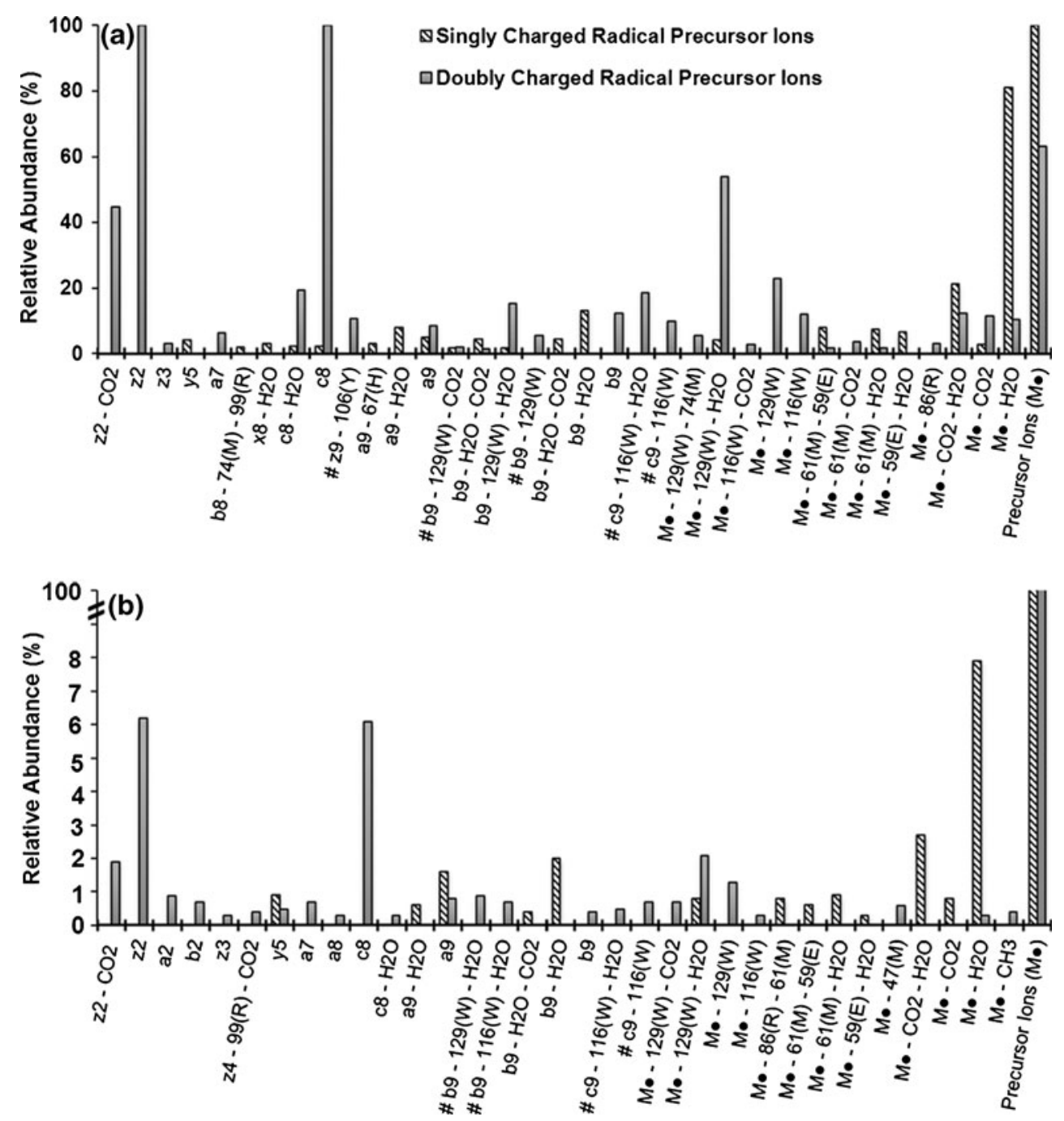

Figure 6. Product ion abundance distribution obtained in $\mathrm{MS}^{3}$ (a) IRMPD and (b) EID of the radical cations of ACTH 1-10. Only the most intense product ions are displayed in the Figure. All backbone product ions are shown in Scheme 4 and a complete list of all observed product ions is given in Supplemental data (Tables S15-S16 and S24-25). For simplicity the charge state of the product ions and hydrogen atom losses are not shown. \# = more than one assignment possible based on $\mathrm{m} / \mathrm{z}$ ratio

being detected in both its singly and doubly protonated forms. Formation of these two complementary product ions corresponded to cleavage at the N-terminal side of tryptophan. It is worth pointing out that ACTH 1-10 was the only peptide for which formation of $c$-type ions represented a dominant fragmentation pathway. Formation of the $\left[z_{2}-2 \mathrm{H}\right]$ product ion can be explained by the unpaired electron being located at the tryptophan and the second hydrogen atom loss resulting from a hydrogen rearrangement. Loss of one and two hydrogen atoms from $z$-type product ions having a tryptophan adjacent to the radical site have been previously reported in ECD [72]. An abundant $\mathrm{CO}_{2}$ loss, presumably from the C-terminus, is observed from the $\left[z_{2}-2 \mathrm{H}\right]^{\circ}$ product ion. Cleavages at the $\mathrm{C}$-terminal side of tryptophan, resulting in the formation of $a_{9}$ and $\left[b_{9}-\mathrm{H}\right]^{\cdot}$ were also observed, in agreement with the results observed for the singly charged counterpart. Nevertheless, cleavages at tryptophan were more dominant and more abundant in the spectrum of the doubly charged radical cations. Interestingly, cleavages associated with the presence of tyrosine were substantially suppressed. Therefore, for this doubly charged peptide, fragmentation was largely controlled by the presence of tryptophan. We can postulate based on these observations that for ACTH 1-10 the radical migrates to tryptophan and through radical rearrangement at the $\pi$ system and at the $\alpha$ - or $\beta$-carbon of the side chain, promotes further fragmentation. Furthermore, the preferential cleavage at tryptophan versus tyrosine can be explained based on their calculated bond dissociation energies ( $\beta$ BDEs), which have been suggested to play an important role in the fragmentation of peptide radical cations [44]. Tryptophan has a lower $\beta$ BDE and therefore cleavages at this residue are more favorable when compared to cleavages at tyrosine featuring higher $\beta$ BDE. Abundant tryptophan side chain loss and/or favored cleavages next to tryptophan were also detected in $\mathrm{MS}^{3} \mathrm{CID}$ of ACTH 1-10 (Figure S3), in agreement with previous observations [17, $38,44]$, and they have also been reported in electron-based 
reactions of protonated and deprotonated peptides containing tryptophan [56, 73-75].

Secondary fragmentation corresponding to $\mathrm{H}_{2} \mathrm{O}$ and $\mathrm{CO}_{2}$ losses and side chain losses from methionine $\left(\mathrm{C}_{3} \mathrm{H}_{6} \mathrm{~S}\right.$ $\left.74.019 \mathrm{Da}, \mathrm{C}_{2} \mathrm{H}_{5} \mathrm{~S}^{\cdot} 61.0112 \mathrm{Da}\right)$ and arginine $\left(\mathrm{C}_{3} \mathrm{H}_{8} \mathrm{~N}_{3} \cdot\right.$ 86.0718 Da) were observed from the product and precursor ions. Similar fragmentation pathways were observed between the $\mathrm{MS}^{3} \mathrm{CID}$ and IRMPD spectra of the doubly charged radical cations of ACTH 1-10 (Figures 6a and S3). One notable difference was the significantly lower intensity of the $\left[z_{2}-2 \mathrm{H}\right]^{\circ}$ in $\mathrm{MS}^{3} \mathrm{CID}$ (Figure S3).

\section{$\mathrm{MS}^{3}$ EID of ACTH 1-10}

\section{Singly Charged Radical Cations $\mathrm{M}^{+\cdot}$}

For the singly charged radical cations of ACTH 1-10, EID yielded only three backbone product ions, $a_{9}, b_{9}-\mathrm{H}_{2} \mathrm{O}$, and $y_{5}$, (Figure 7a and Scheme 4) with $a_{9}$ and $b_{9}-\mathrm{H}_{2} \mathrm{O}$ corresponding to cleavage next to tryptophan. As shown in Figure $6 \mathrm{~b}$, the spectrum was dominated by $\mathrm{CO}_{2}$ and $\mathrm{H}_{2} \mathrm{O}$ losses. Side chain losses from methionine (61.0112 Da), glutamic acid (59.0133 Da), tryptophan (129.058 Da), and arginine $(86.0718 \mathrm{Da})$ were also observed (Figure $6 \mathrm{~b}) . \mathrm{MS}^{3}$ IRMPD and CID of ACTH 1-10 resulted in more backbone product ions and more extensive amino acid side chain losses, but enhanced cleavage at the tryptophan residue was common for all three dissociation techniques.

\section{Doubly Charged Radical Cations $[\mathrm{M}+\mathrm{H}]^{2+}$.}

$\mathrm{MS}^{3}$ EID of the $[\mathrm{M}+\mathrm{H}]^{2+\cdot}$ precursor ions (Figures $6 \mathrm{~b}$ and $7 \mathrm{~b}$ ) resulted in the formation of $a-, b-, c-, y$-, and $z$-type product ions along with amino acid side chain losses from the precursor and product ions. The EID spectrum was governed by preferential cleavage at the $\mathrm{N}$-terminal side of tryptophan to produce the $\left[z_{2}-2 \mathrm{H}\right]^{\prime}$ and $c_{8}$ product ions, and tryptophan side chain loss. These fragmentation patterns were very similar to those obtained in IRMPD and CID, although secondary fragmentation was observed to a lesser extent in EID. Few additional backbone product ions, including $a_{2}, a_{8}, b_{2}, y_{3}$, and $y_{5}$ were only observed in EID (Scheme 4).

\section{$\mathrm{MS}^{3}$ IRMPD of Neurotensin}

\section{Doubly Charged Radical Cations $[M+H]^{2+}$.}

For neurotensin, which was the largest peptide examined here, the $\mathrm{MS}^{3}$ IRMPD spectrum displayed a very large number of product ions (Scheme 5). The resulting spectrum is considerably more complex compared with the $\mathrm{MS}^{3}$ IRMPD spectra of peptide radical cations of angiotensin I, $\left[\mathrm{Ile}^{7}\right]$-angiotensin III, and ACTH 1-10. Many of the product ions corresponded to minor fragmentation pathways as they were detected with low yields. For a number of product ions, multiple assignments were within $10 \mathrm{ppm}$ mass accuracy, complicating spectrum interpretation. For example, the
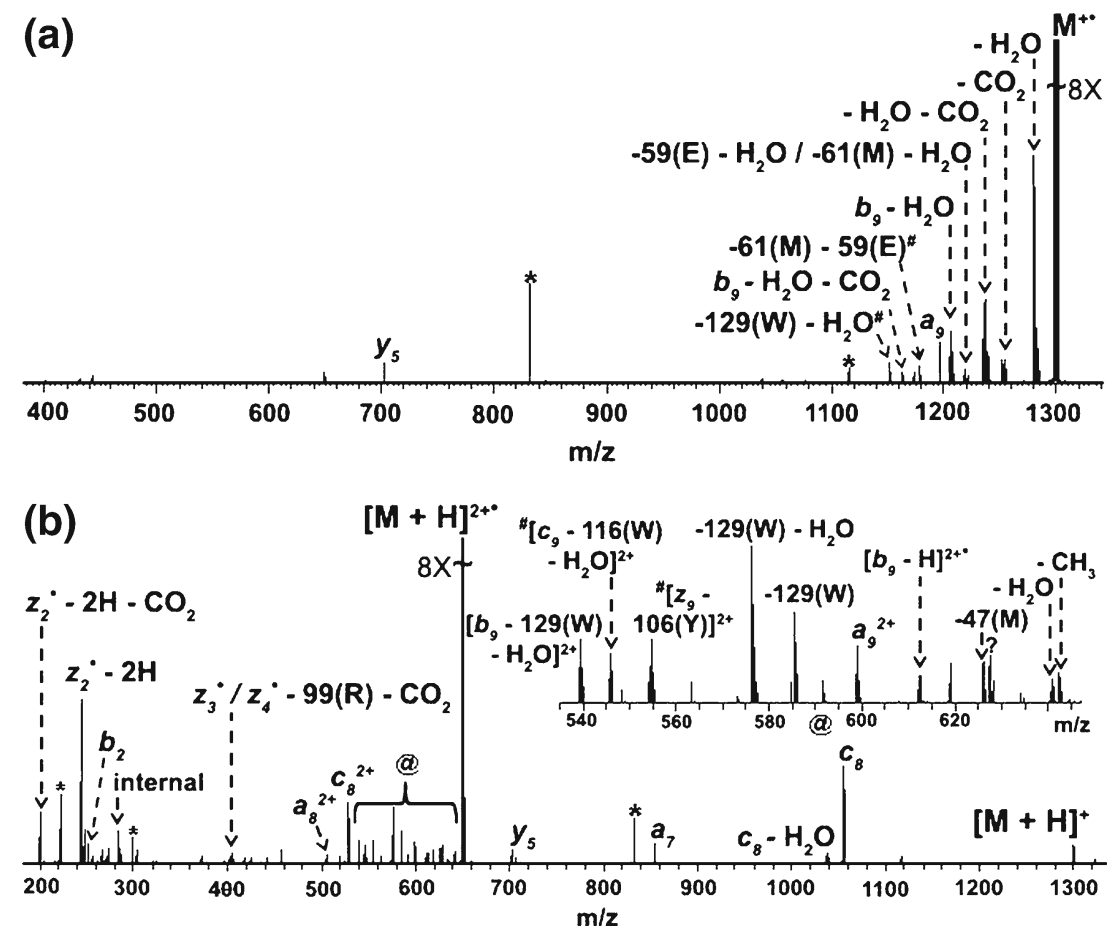

Figure 7. $\mathrm{MS}^{3}$ EID of (a) singly and (b) doubly charged radical cations of ACTH 1-10, SYSMEHFRWG-OH. Very limited backbone bond fragmentation was observed for the singly charged radical cations and the majority of the product ions corresponded to side chain and small neutral loses. By contrast, a large number of backbone product ions were observed for the doubly charged radical precursor ions. A complete list of all generated product ions is given in Supplemental data, Tables S24 and S25. ${ }^{*}=$ noise peak, ? = unidentified product ions, \# = more than one assignment possible based on $\mathrm{m} / \mathrm{z}$ ratio 



Figure 8. Product ion abundance distribution obtained in $\mathrm{MS}^{3}$ (a) IRMPD and (b) EID of the radical cations of neurotensin. Only the major product ions are displayed in the Figure. All backbone product ions are shown in Scheme 4 and a complete list of all observed product ions is given in Supplemental data (Tables S17-S18 and S26-27). For simplicity the charge state of the product ions and hydrogen atom losses are not shown. \# = more than one assignment possible based on $\mathrm{m} / \mathrm{z}$ ratio

product ion detected at $m / z 757.417$ can be assigned as $a_{12}$ or $\left[\mathrm{M}^{*}-59(\mathrm{E})-99(\mathrm{R})\right]$ or $\left[\mathrm{M}^{*}-72(\mathrm{E})-86(\mathrm{R})\right]$. This ion was also detected in the CID spectrum (Figure S4).

Despite the complexity of the spectrum, several fragmentation patterns can be revealed as illustrated in Figure $8 \mathrm{a}$. Formation of $\mathrm{a}_{11}$ product ion corresponding to cleavage at the $\mathrm{C}$-terminal side of tyrosine was dominant. Another abundant product ion, which can be assigned to $x_{10}-44(\mathrm{~N})-59(\mathrm{E})$, and/or $z_{10}-44(\mathrm{~N})-\mathrm{NH}_{3}$, corresponded to cleavage at the $\mathrm{C}$-terminal side of the second tyrosine residue. Dominant were also product ions corresponding to leucine $\left(\mathrm{C}_{3} \mathrm{H}_{7}{ }^{\circ} 43.0548 \mathrm{Da}, \mathrm{C}_{4} \mathrm{H}_{8}\right.$ $56.0626 \mathrm{Da})$, glutamic acid $\left(\mathrm{C}_{2} \mathrm{H}_{3} \mathrm{O}_{2}{ }^{\circ} 59.0133 \mathrm{Da}\right.$, $\left.\mathrm{C}_{2} \mathrm{H}_{4} \mathrm{O}_{2} 72.0211 \mathrm{Da}\right)$, and lysine $\left(\mathrm{C}_{4} \mathrm{H}_{9} \mathrm{~N} 71.0735 \mathrm{Da}\right)$ side chain losses. Another abundant product ion, detected at $m / z=750.9002$, can be assigned as $c_{12}-58(\mathrm{~K})$ and/or $x_{12}-44(\mathrm{~N})-43(\mathrm{~L})$. The majority of backbone product ions exhibited extensive secondary fragmentation corresponding to amino acid side chain losses, similar to the results obtained for ACTH 1-10. In addition, several other backbone product ions were observed. Those were detected with significantly lower abundances when compared to side chain losses from the radical precursor ions and formation of the $a_{11}$ product ion.

Although similar fragmentations pathways were observed between MS $^{3}$ IRMPD and CID of the doubly charged radical cations of neurotensin, in CID, side chain loss from leucine, dominated the spectrum $\left(\mathrm{C}_{3} \mathrm{H}_{7}{ }^{\cdot} 43.0548 \mathrm{Da}\right)$ (Figure S4). In IRMPD several fragmentation pathways were favored and their corresponding product ions were detected with similar intensities.

\section{Triply Charged Radical Cations $[\mathrm{M}+2 \mathrm{H}]^{3+\cdot}$}

$\mathrm{MS}^{3}$ IRMPD of the triply charged radical cations of neurotensin (Figure 8a) resulted mainly in side chain losses from leucine, glutamic acid, arginine, and tyrosine. In terms of backbone fragmentation the most abundant product ions were the $a_{11}$ and $x_{10}-44(\mathrm{~N})-59(\mathrm{E})\left(\right.$ and/or $z_{10}-44(\mathrm{~N})-$ $\mathrm{NH}_{3}$ ) both corresponding to cleavages next to the two 
tyrosines. A large number of backbone product ions, mainly $a-, b$ - and $y$-, was also observed (Scheme 5), but these product ions were of lower intensity. The vast majority of backbone product ions exhibited extensive secondary fragmentation corresponding to amino acid side chain losses. The fragmentation pathways observed for the triply charged radical cations were very similar to those observed for the doubly charged species, although some product ions were only detected for the doubly or triply charged species.

The majority of amino acid side chain losses observed in $\mathrm{MS}^{3}$ IRMPD of the triply charged radical cations of neurotensin was also present in the $\mathrm{MS}^{3} \mathrm{CID}$ spectrum. Abundant formation of the $\mathrm{a}_{11}$ product ion was common for both dissociation techniques and fragmentation associated with tyrosine, either through side chain loss or backbone fragmentation, was favorable. Significant differences in backbone product ion abundances, with the exception of $a_{11}$, were apparent. Furthermore some backbone product ions were unique for CID or IRMPD (Scheme 5). For example, following CID, the backbone product ions $y_{10}, y_{11}$, and $z_{10}$ were detected with high abundances (Figure S4). In IRMPD, the $y_{10}$ was absent and the latter two were detected with very low intensities.

\section{$\mathrm{MS}^{3}$ EID of Neurotensin}

\section{Doubly Charged Radical Cations $\left[\mathrm{M}+\mathrm{H}^{2+}\right.$.}

$\mathrm{MS}^{3}$ EID of the doubly charged radical cations of neurotensin resulted in extensive fragmentation (Figure $8 \mathrm{~b}$ and Scheme 5). The most abundant product ion in the EID spectrum was the $\mathrm{a}_{11}$ product ion followed by the triply charged electron ionized species, $[\mathrm{M}+\mathrm{H}]^{3+\cdot \cdot}$, at $\mathrm{m} / \mathrm{z}=$ 557.6408. The $\mathrm{a}_{11}$ product ion corresponds to cleavage next to tyrosine at position 11 .

Similar to IRMPD and CID, several side chain losses were observed following EID (Figure 8b). A major difference between EID and IRMPD was that in EID amino acid side chain losses from the precursor and product ions were suppressed and a large number of backbone product ions were detected with relatively high yields, resulting in a considerably less complex spectrum (Figure 8). These backbone product ions include $a$-, $b-, c-, y$-, $x$-and $z$-type product ions, and with the exception of $a_{11}$ and $a_{12}$, they were detected with comparable yields. The $a_{12}$ product ion corresponded to cleavage $\mathrm{C}$-terminal to tyrosine. Internal product ions detected at low $\mathrm{m} / \mathrm{z}$ ratios were also present in EID, but were absent in CID and very few were observed following IRMPD.

\section{Triply Charged Radical Cations $[M+2 H]^{3+\cdot}$}

$\mathrm{MS}^{3}$ EID of the $[\mathrm{M}+2 \mathrm{H}]^{3+\cdot}$ precursor ions of neurotensin yielded extensive backbone bond cleavages resulting in the formation of a wide range of product ion types. Product ions resulting from charge, i.e., $b$ - and $y$-, and radical mediated fragmentation, i.e., side chain losses, $a$-, $c$-, $x$-, and $z$-, were detected with comparable yields (Figure $8 \mathrm{~b}$ ). Backbone bond fragmentation next to aromatic residues was apparent from the formation of $z_{10}-\mathrm{CO}_{2}-\mathrm{NH}_{3}$ [and/or $x_{10}-44(\mathrm{~N})-59(\mathrm{E})$ ], $a_{3}$ and $a_{11}$ product ions. The latter was detected as both a doubly and triply protonated ion. In terms of charge mediated fragmentation the most abundant product ions were $y_{2}$, $y_{4}, y_{7}-2 \mathrm{H}, y_{9}$, and $b_{3}$. Furthermore, abundant internal product ions were present.

EID resulted in a larger number of backbone product ions when compared to IRMPD and CID, but side chain losses were analogous to those detected in $\mathrm{MS}^{3} \mathrm{CID}$ and IRMPD (Scheme 5 and Figure $8 b$ ). Furthermore, following IRMPD of neurotensin, radical mediated fragmentation was more favorable, whereas in EID charge and radical driven processes contributed more equally to the dissociation outcome. Both the doubly and triply charged radical cations resulted in extensive backbone bond fragmentation, but as noted for the other peptides examined, several product ions were unique for each charge state (Scheme 5). Furthermore, for the doubly charged species cleavage next to tyrosine to produce the $a_{11}$ ion was more dominant compared with charge directed fragmentation. For the most part, common amino acid side chain losses were observed for both charge states.

\section{Fragmentation of Singly, [M] ${ }^{+*}$, Versus Doubly, $[\mathrm{M}+\mathrm{H}]^{2+}$, and Triply, $[\mathrm{M}+2 \mathrm{H}]^{3+\cdot}$, Charged Radical Cations}

For all peptide radical cations examined here, doubly and triply charged species exhibited more extensive fragmentation than their singly charged counterparts, regardless of the activation technique employed for fragmentation (Figures 2, 4, 6, and 8 and S1-S4). The formation of many of these product ions was due to dissociation channels, including both radical and charge driven processes, not observed for the singly charged species, suggesting that a wider range of fragmentation pathways are accessible for doubly and triply charged radical cations.

$\mathrm{MS}^{3}$ CID, IRMPD, and EID fragmentation of the $\mathrm{M}^{+}$ precursor ions was mainly governed by radical driven dissociation. These observations are in agreement with previous reports, in which it was suggested that the arginine residue sequesters the proton and fragmentation proceeds through radical directed process [32, 34, 70].

For doubly and triply charged radical cations, due to the addition of the extra proton(s), charge mediated fragmentation to produce $b$ - and $y$-type product ions became also favorable (Figures 2, 4, 6, and 8 and S1-S4). These results suggest that for doubly and triply charged peptides examined herein the charge state also plays a role in the dissociation outcome of radical cations by promoting charge driven fragmentation. Interestingly, the majority of dissociation pathways observed for the singly charged species that were radical driven were still present in the spectra of $[\mathrm{M}+\mathrm{H}]^{2+}$. 
and $[\mathrm{M}+2 \mathrm{H}]^{3+\cdot}$. It should be pointed out, though, that the relative intensities of common product ions were different for each charge state. In general, we observed that the relative abundance of $a$-type product ions decreased for doubly and triply charged radical cations when compared to that observed for the singly charged species, suggesting competing fragmentation pathways. Side chain losses did not follow this trend, i.e., some were more abundant for the doubly and triply charged species and some were more dominant for the singly charged counterpart. Regardless of product ions abundances, for $[\mathrm{M}+\mathrm{H}]^{2+\cdot}$ and $[\mathrm{M}+2 \mathrm{H}]^{3+\text {. }}$ precursor ions both radical and charge directed processes contributed to the dissociation outcome. In contrast, singly charged species examined herein fragment mainly through radical driven dissociation, presumably due to the presence of the arginine residue.

It is worth noting that several product ions, i.e., $a-, c-, z-$, and $x$-, and side chain losses, which are believed to be formed through radical mediated fragmentation $[21,36,38$, $40,44]$, were present in the spectra of the doubly and triply charged radical cations but were absent for the singly charged species. Several factors may attribute to this behavior. For singly charged species, charge localization at a specific residue, i.e., arginine, will prevent detection of product ions not containing a charge since these will be neutral and therefore not detectable. Increasing the peptide charge state increases the probability of product ions being charged and therefore detectable. This assumption is in agreement with the results obtained in MS ${ }^{3}$ IRMPD and EID of the singly charged radical cations for which all observed product ions contained the basic arginine residue. For $\mathrm{MS}^{3}$ CID few product ions not containing the basic arginine were present, but these were detected with low intensities. For doubly and triply charged species, product ions not containing the arginine residue were detected. Most of these product ions contained a histidine residue.

Another possible explanation is that the second charge lowers additional dissociation barriers or increases radical mobility and therefore allows new backbone bonds to become accessible to radical initiated fragmentation.

Peptide gas phase structure is an additional factor, which can affect the dissociation outcome, and it is very likely that peptide charge state can affect gas phase structure. Furthermore, Laskin and coworkers suggested that depending on the structure and the binding mode of the peptide to the metal complex, different peptide gas phase structures can be generated [39]. The authors showed that for angiotensin III and its methylated analogue, two different populations of radical cations exist due to different binding modes, neutral versus zwitterionic coordination, to the metal complex. Differences between threshold energies and activation entropies were observed for the two populations [39]. We can therefore postulate that the binding mode of the peptide to the metal complex can be affected by the peptide charge state and, therefore, different gas phase structures will be generated from different peptide charge states. For instance, an abundant $\mathrm{CO}_{2}$ loss was observed from the singly charged radical cations of $\left[\mathrm{Ile}^{7}\right]$-angiotensin III, whereas this loss was absent for the doubly and triply charged counterparts (Figures 4 and S2). Based on this observation and on previous reports $[32,34,39]$, we can speculate that singly charged species of $\left[\mathrm{Ile}^{7}\right]$-angiotensin III bind to the metal complex as a zwitterion via the $\mathrm{C}$-terminal carboxylate group and upon $\mathrm{CID}$ of the $\left[\mathrm{Cu}(\mathrm{II})(\text { terpy)M}]^{2+\cdot}\right.$ complex, the resulting carboxylate radical undergoes facile $\mathrm{CO}_{2}$ loss. For the doubly and triply charged species, no $\mathrm{CO}_{2}$ loss was observed, suggesting different binding modes of the peptide to the metal complex and possible generation of different peptide gas phase structures upon CID. Therefore, differences in fragmentation behavior can be attributed to different peptide gas phase structures as a result of the peptide charge state and the binding mode to the metal complex.

Doubly and triply charged radical cations exhibited very similar fragmentation, with the majority of product ions being detected from both charge states, but some backbone product ions and amino acid side chain loses were unique for each charge state (Figures 2, 4, 6, and 8 and S1-S4). Differences in fragmentation behavior between doubly and triply charged species can be attributed to the addition of the third charge, differences in charge location, and peptide gas phase structure, as discussed above.

\section{Conclusions}

We have investigated $\mathrm{MS}^{3}$ IRMPD and EID of singly, doubly, and triply charged radical cations produced by CID of their corresponding $\left[\mathrm{Cu}^{(\mathrm{II})}(\text { terpy })(\mathrm{M}+\mathrm{nH})\right]^{(\mathrm{n}+2)+\cdot}$ complexes and compared the observed fragmentation pathways with those obtained in $\mathrm{MS}^{3} \mathrm{CID}$. Our results demonstrated that dissociation of hydrogen deficient peptide radical cations was highly dynamic and diverse. Although several common fragmentation pathways were present for all peptides and all charge states examined, several others were unique for each peptide, charge state, and method of ion activation.

Similar amino acid side chain losses, characteristic of radical mediated dissociation, were detected for all peptides and all three charge states examined, regardless of the dissociation technique employed. These side chain cleavages were dominant and were observed from both the precursor and product ions. In general, side chain losses were less extensive following EID.

Favorable cleavages at aromatic residues (His, Tyr, Trp, Phe), either through side chain losses or backbone bond fragmentation, represented another common fragmentation pathway. Our observations are in agreement with the results obtained from Julian et al. [44] who suggested that aromatic residues, due to their low $\beta$ BDEs, are among the most competitive sites for $\beta$ radical formation rendering them as the most favorite sites for backbone fragmentation.

$M^{3}$ CID, IRMPD and EID of singly charged radical cations were governed by radical driven dissociation result- 
ing, mainly in the formation of $a$-type product ions and/or side chain losses. For ACTH 1-10, in addition to side chain losses and formation of $a$-type product ions, $b-, y-, c$-, and $x$ type product ions were also detected with relatively high yields, suggesting that amino acid composition and charge location may also influence the dissociation outcome. These results are analogous to those previously reported in $\mathrm{MS}^{3}$ CID of radical cations [16, 36, 40, 44, 71].

Fragmentation of doubly and triply charged radical cations was governed by both radical and charge driven processes. A wide range of product ions, including, $a-, b-$, $c-, y-, x$-, and $z$-type, was observed, resulting in more extensive fragmentation compared with that obtained for the singly charged species. It is worth noting that several of these additional product ions, i.e., $a$-, $x$-, and $z$-type were due to radical directed fragmentation, but were absent from the spectra of the singly charged species. Differences in fragmentation behavior between singly and doubly, triply charged radical cations can be attributed to several factors such as the addition of the extra charge(s), (which will increase the probability of product ions being charged and therefore detectable), differences in peptide gas phase structures, lower dissociation barriers, and increased radical mobility.

Despite the similarities between the spectra of the doubly and triply charged species and between $\mathrm{MS}^{3}$ CID, IRMPD, and EID, some differences were notable. Several backbone product ions and side chain losses were unique for each charge state or dissociation method. Furthermore, differences in the relative abundances of the product ions with respect to each other were observed between $\mathrm{MS}^{3} \mathrm{CID}$, IRMPD, and EID. For doubly and triply charged radical precursor ions, the dominant fragmentation pathways, radical or charge driven, were highly dependent on peptide charge state, amino acid composition, and dissociation technique employed for fragmentation. Overall, gas phase dissociation of highly charged radical cations provided rich sequence information, which cannot be obtained from the even electron precursor ions following vibrational excitation.

\section{Acknowledgment}

The authors acknowledge support for this work by the Beckman Institute and the Gordon and Betty Moore Foundation.

\section{References}

1. Budnik, B.A., Zubarev, R.A.: $\mathrm{MH}^{2+}{ }^{\circ}$ ion production from protonated polypeptides by electron impact: Observation and determination of ionization energies and a cross-section. Chem. Phys. Lett. 316, 19-23 (2000)

2. Zubarev, R.A., Nielsen, M.L., Budnik, B.A.: Tandem ionization mass spectrometry of biomolecules. Eur. J. Mass Spectrom. 6, 235-240 (2000)

3. Sorensen, M., Forster, J.S., Hvelplund, P., Jorgensen, T.J.D., Nielsen, S. B., Tomita, S.: On the formation of radical dications of protonated amino acids in a "microsolution" of water or acetonitrile and their reactivity towards the solvent. Chem. Eur. J. 7, 3214-3222 (2001)

4. Nielsen, S.B., Andersen, J.U., Hvelplund, P., Jorgensen, T.J.D., Sorensen, M., Tomita, S.: Triply charged bradykinin and gramicidin radical cations: Their formation and the selective enhancement of charge-directed cleavage processes. Int. J. Mass Spectrom. 213, 225 235 (2002)

5. Hvelplund, P., Nielsen, S.B., Sorensen, M., Andersen, J.U., Jorgensen, T.J.D.: Electron loss from multiply protonated lysozyme ions in high energy collisions with molecular oxygen. J. Am. Soc. Mass Spectrom. 12, 889-893 (2001)

6. Kalcic, C.L., Gunaratne, T.C., Jonest, A.D., Dantus, M., Reid, G.E.: Femtosecond laser-induced ionization/dissociation of protonated peptides. J. Am. Chem. Soc. 131, 940-942 (2009)

7. Hao, G., Gross, S.S.: Electrospray tandem mass spectrometry analysis of S- and N-nitrosopeptides: Facile loss of NO and radical-induced fagmentation. J. Am. Soc. Mass. Spectrom. 17, 1725-1730 (2006)

8. Hodyss, R., Cox, H.A., Beauchamp, J.L.: Bioconjugates for tunable peptide fragmentation: Free Radical Initiated Peptide Sequencing (FRIPS). J. Am. Chem. Soc. 127, 12436-12437 (2005)

9. Knudsen, E.R., Julian, R.R.: Fragmentation chemistry observed in hydrogen deficient radical peptides generated from N-nitrosotryptophan residues. Int. J. Mass Spectrom. 294, 83-87 (2010)

10. Ly, T., Julian, R.R.: Residue-specific radical-directed dissociation of whole proteins in the gas phase. J. Am. Chem. Soc. 130, 351-358 (2008)

11. Ly, T., Julian, R.R.: Tracking radical migration in large hydrogen deficient peptides with covalent labels: Facile movement does not equal indiscriminate fragmentation. J. Am. Soc. Mass Spectrom. 20, 11481158 (2009)

12. Masterson, D.S., Yin, H.Y., Chacon, A., Hachey, D.L., Norris, J.L., Porter, N.A.: Lysine peroxycarbamates: Free radical-promoted peptide cleavage. J. Am. Chem. Soc. 126, 720-721 (2004)

13. Yin, H., Chacon, A., Porter, N.A., Yin, H.Y., Masterson, D.S.: Free radical-induced site-specific peptide cleavage in the gas phase: Lowenergy collision-induced dissociation in ESI- and MALDI mass spectrometry. J. Am. Soc. Mass Spectrom. 18, 807-816 (2007)

14. Lloyd, J.R., Hess, S.: Peptide fragmentation by corona discharge induced electrochemical ionization. J. Am. Soc. Mass Spectrom. 21, 2051-2061 (2010)

15. Chu, I.K., Rodriquez, C.F., Lau, T.C., Hopkinson, A.C., Siu, K.W.M.: Molecular radical cations of oligopeptides. J. Phys. Chem. B 104, 33933397 (2000)

16. Chu, I.K., Rodriguez, C.F., Hopkinson, A.C., Siu, K.W.M., Lau, T.C.: Formation of molecular radical cations of enkephalin derivatives via collision-induced dissociation of electrospray-generated copper (II) complex ions of amines and peptides. J. Am. Soc. Mass Spectrom. 12, 1114-1119 (2001)

17. Bagheri-Majdi, E., Ke, Y.Y., Orlova, G., Chu, I.K., Hopkinson, A.C., Siu, K.W.M.: Copper-mediated peptide radical ions in the gas phase. $J$. Phys. Chem. B 108, 11170-11181 (2004)

18. Barlow, C.K., Wee, S., McFadyen, W.D., O'Hair, R.A.J.: Designing copper(II)ternary complexes to generate radical cations of peptides in the gas phase: Role of the auxiliary ligand. Dalton Trans. 3199-3204 (2004)

19. Chu, I.K., Siu, S.O., Lam, C.N.W., Chan, J.C.Y., Rodriquez, C.F.: Formation of molecular radical cations of aliphatic tripeptides from their complexes with $\mathrm{Cu}-\mathrm{II}(12$-crown-4). Rapid Comm. Mass Spectrom. 18, 1798-1802 (2004)

20. Barlow, C.K., McFadyen, W.D., O'Hair, R.A.J.: Formation of cationic peptide radicals by gas-phase redox reactions with trivalent chromium, manganese, iron, and cobalt complexes. J. Am. Chem. Soc. 127, 6109$6115(2005)$

21. Chu, I.K., Lam, C.N.W.: Generation of peptide radical dications via low-energy collision-induced dissociation of [Cu-II(terpy)(M+H)]( $3+)$. $J$. Am. Soc. Mass Spectrom. 16, 1795-1804 (2005)

22. Chu, I.K., Lam, C.N.W., Siu, S.O.: Facile generation of tripeptide radical cations in vacuo via intramolecular electron transfer in $\mathrm{Cu}-\mathrm{II}$ tripeptide complexes containing sterically encumbered terpyridine ligands. J. Am. Soc. Mass Spectrom. 16, 763-771 (2005)

23. Lam, C.N.W., Ruan, E.D.L., Ma, C.Y., Chu, I.K.: Non-zwitterionic structures of aliphatic-only peptides mediated the formation and dissociation of gas phase radical cations. J. Mass Spectrom. 41, 931938 (2006)

24. Lam, C.N.W., Siu, S.O., Orlova, G., Chu, I.K.: Macrocyclic effect of auxiliary ligand on the gas-phase dissociation of ternary copper(II)GGX complexes. Rapid Comm. Mass Spectrom. 20, 790-796 (2006)

25. Wee, S., Mortimer, A., Moran, D., Wright, A., Barlow, C.K., O’Hair, R. A.J., Radom, L., Easton, C.J.: Gas-phase regiocontrolled generation of 
charged amino acid and peptide radicals. Chem. Commun. 4233-4235 (2006)

26. Turecek, F., Holm, A.I.S., Panja, S., Nielsen, S.B., Hvelplund, P.: Transition metals as electron traps. II. Structures, energetics and electron transfer dissociations of ternary $\mathrm{Co}, \mathrm{Ni}$ and $\mathrm{Zn}$-peptide complexes in the gas phase. J. Mass Spectrom. 44, 1518-1531 (2009)

27. Hopkinson, A.C., Siu, K.W.M.: Peptide radical cations. In: Laskin, J., Lifshitz, C. (eds.) Principles of Mass Spectrometry Applied to Biomolecules, pp. 301-335. Wiley, Hoboken, NJ (2006)

28. Karnezis, A., Barlow, C.K., O’Hair, R.A.J., McFadyen, W.D.: Peptide derivatization as a strategy to form fixed-charge peptide radicals. Rapid Comm. Mass Spectrom. 20, 2865-2870 (2006)

29. Ke, Y., Zhao, J., Verkerk, U.H., Hopkinson, A.C., Siu, K.W.M.: Histidine, lysine, arginine radical cations: Isomer control via the choice of auxiliary ligand $(\mathrm{L})$ in the dissociation of $[\mathrm{Cu}-\mathrm{II}(\mathrm{L})($ amino acid) $](\cdot 2+)$ complexes. J. Phys. Chem. B 111, 14318-14328 (2007)

30. Barlow, C.K., Moran, D., Radom, L., McFadyen, W.D., O'Hair, R.A.J.: Metal-mediated formation of gas-phase amino acid radical cations. $J$. Phys. Chem. A 110, 8304-8315 (2006)

31. Laskin, J., Yang, Z., Chu, I.K.: Energetics and dynamics of electron transfer and proton transfer in dissociation of Metal III(salen)peptide complexes in the gas phase. J. Am. Chem. Soc. 130, 3218$3230(2008)$

32. Wee, S., O'Hair, R.A.J., McFadyen, W.D.: The role of the position of the basic residue in the generation and fragmentation of peptide radical cations. Int. J. Mass Spectrom. 249, 171-183 (2006)

33. Wee, S., O'Hair, R.A.J., McFadyen, W.D.: Side-chain radical losses from radical cations allows distinction of leucine and isoleucine residues in the isomeric peptides Gly-XXX-Arg. Rapid Comm. Mass Spectrom. 16, 884-890 (2002)

34. Wee, S., O'Hair, R.A.J., McFadyen, W.D.: Comparing the gas-phase fragmentation reactions of protonated and radical cations of the tripeptides GXR. Int. J. Mass Spectrom. 234, 101-122 (2004)

35. Laskin, J., Futrell, J.H., Chu, I.K.: Is dissociation of peptide radical cations an ergodic process? J. Am. Chem. Soc. 129, 9598-9599 (2007)

36. Laskin, J., Yang, Z.B., Lam, C., Chu, I.K.: Charge-remote fragmentation of odd-electron peptide ions. Anal. Chem. 79, 66076614 (2007)

37. Chu, I.K., Zhao, J., Xu, M., Siu, S.O., Hopkinson, A.C., Siu, K.W.M.: Are the radical centers in peptide radical cations mobile? the generation, tautomerism, and dissociation of isomeric $\alpha$-carbon-centered triglycine radical cations in the gas phase. J. Am. Chem. Soc. 130, 7862-7872 (2008)

38. Siu, C.K., Ke, Y.Y., Orlova, G., Hopkinson, A.C., Siu, K.W.M.: Dissociation of the $\mathrm{N}-\mathrm{C} \alpha$ bond and competitive formation of the $[\mathrm{z}(\mathrm{n})-\mathrm{H}](++)$ and $[\mathrm{c}(\mathrm{n})+2 \mathrm{H}](+)$ product ions in radical peptide ions containing tyrosine and tryptophan: The influence of proton affinities on product formation. J. Am. Soc. Mass Spectrom. 19, 1799-1807 (2008)

39. Yang, Z.B., Lam, C., Chu, I.K., Laskin, J.: The effect of the secondary structure on dissociation of peptide radical cations: Fragmentation of angiotensin III and its analogues. J. Phys. Chem. B 112, 12468-12478 (2008)

40. Laskin, J., Yang, Z.B., Ng, C.M.D., Chu, I.K.: Fragmentation of $\alpha$ radical cations of arginine-containing peptides. J. Am. Soc. Mass Spectrom. 21, 511-521 (2010)

41. Ng, D.C.M., Song, T., Siu, S.O., Siu, C.K., Laskin, J., Chut, I.K. Formation, isomerization, and dissociation of $\alpha$-carbon-centered and picentered glycylglycyltryptophan radical cations. J. Phys. Chem. B 114, 2270-2280 (2010)

42. Moore, B.N., Blanksby, S.J., Julian, R.R.: Ion-molecule reactions reveal facile radical migration in peptides. Chem. Commun. 5015-5017 (2009)

43. Hopkinson, A.C.: Radical cations of amino acids and peptides: Structures and stabilities. Mass Spectrom. Rev. 28, 655-671 (2009)

44. Sun, Q.Y., Nelson, H., Ly, T., Stoltz, B.M., Julian, R.R.: Side chain chemistry mediates backbone fragmentation in hydrogen deficient peptide radicals. J. Proteome Res. 8, 958-966 (2009)

45. Liu, H.C., Hakansson, K., Lee, J.Y., Sherman, D.H.: Collisionactivated dissociation, infrared multiphoton dissociation, and electron capture dissociation of the bacillus anthracis siderophore petrobactin and its metal ion complexes. J. Am. Soc. Mass Spectrom. 18, 842849 (2007)
46. Keller, K.M., Brodbelt, J.S.: Collisionally activated dissociation and infrared multiphoton dissociation of oligonucleotides in a quadrupole ion trap. Anal. Biochem. 326, 200-210 (2004)

47. Crowe, M.C., Brodbelt, J.S.: Infrared multiphoton dissociation (IRMPD) and collisionally activated dissociation of peptides in a quadrupole ion trap with selective IRMPD of phosphopeptides. J. Am. Soc. Mass Spectrom. 15, 1581-1592 (2004)

48. Goolsby, B.J., Brodbelt, J.S.: Tandem infrared multiphoton dissociation and collisionally activated dissociation techniques in a quadrupole ion trap. Anal. Chem. 73, 1270-1276 (2001)

49. Wang, B.H., McLafferty, F.W.: Electron-impact excitation of ions from larger organic-molecules. Org. Mass Spectrom. 25, 554-556 (1990)

50. Cody, R.B., Freiser, B.S.: Electron-impact excitation of ions from organics - alternative to collision-induced dissociation. Anal. Chem. 51, 547-551 (1979)

51. Cody, R.B., Freiser, B.S.: Electron-impact excitation of ions on Fouriertransform mass spectrometry. Anal. Chem. 59, 1054-1056 (1987)

52. Gord, J.R., Horning, S.R., Wood, J.M., Cooks, R.G., Freiser, B.S.: Energy deposition during electron-induced dissociation. J. Am. Soc. Mass Spectrom. 4, 145-151 (1993)

53. Nielsen, M.L., Budnik, B.A., Haselmann, K.F., Olsen, J.V., Zubarev, R.A.: Intramolecular hydrogen atom transfer in hydrogen-deficient polypeptide radical cations. Chem. Phys. Lett. 330, $558-562(2000)$

54. Fung, Y.M.E., Adams, C.M., Zubarev, R.A.: Electron ionization dissociation of singly and multiply charged peptides. J. Am. Chem. Soc. 131, 9977-9985 (2009)

55. Nielsen, M.L., Budnik, B.A., Haselmann, K.F., Zubarev, R.A.: Tandem MALDI/El ionization for tandem Fourier transform ion cyclotron resonance mass spectrometry of polypeptides. Int. J. Mass Spectrom. 226, 181-187 (2003)

56. Lioe, H., O'Hair, R.A.J.: Comparison of collision-induced dissociation and electron-induced dissociation of singly protonated aromatic amino acids. Cystine and related simple peptides using a hybrid linear ion trapFT-ICR mass spectrometer. Anal. Bioanal. Chem. 389, 1429-1437 (2007)

57. Ly, T., Yin, S., Loo, J.A., Julian, R.R.: Electron-induced dissociation of protonated peptides yields backbone fragmentation consistent with a hydrogen-deficient radical. Rapid Comm. Mass Spectrom. 23, 2099$2101(2009)$

58. Feketeova, L., Khairallah, G.N., Hair, R.A.J.: Letter: Intercluster chemistry of protonated and sodiated betaine dimers upon collision induced dissociation and electron induced dissociation. Eur. J. Mass Spectrom. 14, 107-110 (2008)

59. Budnik, B.A., Haselmann, K.F., Elkin, Y.N., Gorbach, V.I., Zubarev, R.A.: Applications of electron-ion dissociation reactions for analysis of polycationic chitooligosaccharides in Fourier transform mass spectrometry. Anal. Chem. 75, 5994-6001 (2003)

60. Yoo, H.J., Hakansson, K.: Determination of double bond location in fatty acids by manganese adduction and electron induced dissociation. Anal. Chem. 82, 6940-6946 (2010)

61. Kaczorowska, M.A., Cooper, H.J.: Electron induced dissociation: A mass spectrometry technique for the structural analysis of trinuclear oxo-centred carboxylate-bridged iron complexes. J. Am. Soc. Mass Spectrom. 21, 1398-1403 (2010)

62. Kalli, A., Grigorean, G., Hakansson, K.: Electron induced dissociation of singly charged peptide anions. J. Am. Soc. Mass Spectrom. Accepted. (2011)

63. Yoo, H.J., Liu, H.C., Hakansson, K.: Infrared multiphoton dissociation and electron-induced dissociation as alternative MS/ MS strategies for metabolite identification. Anal. Chem. 79, 78587866 (2007)

64. Wolff, J.J., Laremore, T.N., Aslam, H., Linhardt, R.J., Amster, I.J.: Electron-induced dissociation of glycosaminoglycan tetrasaccharides. $J$. Am. Soc. Mass Spectrom. 19, 1449-1458 (2008)

65. Feketeova, L., Ryzhov, V., O'Hair, R.A.J.: Comparison of collisionversus electron-induced dissociation of $\mathrm{Pt}(\mathrm{II})$ ternary complexes of histidine- and methionine-containing peptides. Rapid Comm. Mass Spectrom. 23, 3133-3143 (2009)

66. Feketeova, L., O'Hair, R.A.J.: Electron-induced dissociation of doubly protonated betaine clusters: Controlling fragmentation chemistry through electron energy. Rapid Comm. Mass Spectrom. 23, 32593263 (2009) 
67. Feketeova, L., Khairallah, G.N., Brunet, C., Lemoine, J., Antoine, R., Dugourd, P., O'Hair, R.A.J.: Fragmentation of the tryptophan cluster [Trp(9)-2H](2-) induced by different activation methods. Rapid Comm. Mass Spectrom. 24, 3255-3260 (2010)

68. Castro, I., Faus, J., Julve, M., Gleizes, A.: Complex-formation between oxalate and $\left(2,2^{\prime}-6^{\prime}, 2^{\prime \prime}\right.$-terpyridyl)-copper(II) in dimethylsulfoxide solution - synthesis and crystal-structures of mononuclear and dinuclear complexes. J. Chem. Soc. Dalton Trans. 1937-1944 (1991)

69. Han, H., Xia, Y., McLuckey, S.A.: Ion trap collisional activation of c and $\mathrm{z}$ ions formed via gas-phase ion/ion electron-transfer dissociation. J. Proteome Res. 6, 3062-3069 (2007)

70. Xu, M., Song, T., Quan, Q., Hao, Q., Fang, D.C., Siu, C.K., Chu, I.K.: Effect of the N-terminal basic residue on facile $\mathrm{C} \alpha-\mathrm{C}$ bond cleavages of aromatic-containing peptide radical cations. Phys. Chem. Chem. Phys. 13, 5888-5896 (2011)
71. Zhang, L.Y., Reilly, J.P.: Radical-driven dissociation of odd-electron peptide radical ions produced in $157 \mathrm{~nm}$ photodissociation. J. Am. Soc. Mass Spectrom. 20, 1378-1390 (2009)

72. Savitski, M.M., Kjeldsen, F., Nielsen, M.L., Zubarev, R.A.: Hydrogen rearrangement to and from radical $\mathrm{z}$ fragments in electron capture dissociation of peptides. J. Am. Soc. Mass Spectrom. 18, 113-120 (2007)

73. Haselmann, K.F., Budnik, B.A., Kjeldsen, F., Polfer, N.C., Zubarev, R. A.: Can the $(\mathrm{M}-\mathrm{X})$ region in electron capture dissociation provide reliable information on amino acid composition of polypeptides? Eur. $J$. Mass Spectrom. 8, 461-469 (2002)

74. Kruger, N.A., Zubarev, R.A., Carpenter, B.K., Kelleher, N.L., Horn, D. M., McLafferty, F.W.: Electron capture versus energetic dissociation of protein ions. Int. J. Mass Spectrom. 182, 1-5 (1999)

75. Kalli, A., Hakansson, K.: Preferential cleavage of S-S and C-S bonds in electron detachment dissociation and infrared multiphoton dissociation of disulfide-linked peptide anions. Int. J. Mass Spectrom. 263, 71-81 (2007) 